\title{
El tiempo necesario para el florecimiento humano. La gran utopía
}

\author{
Araceli Damián
}

De acuerdo con el enfoque del florecimiento humano es mediante el trabajo que los individuos pueden desplegar todas sus capacidades y necesidades humanas. Este artículo discute la posibilidad de alcanzar el florecimiento humano en una sociedad dividida en clases, como la capitalista, dado el carácter alienado del trabajo. Cuestiona también la idea de que el tiempo libre pueda ser el espacio para alcanzar el florecimiento humano, dada la creciente alienación a la que está sujeto, que se manifiesta en la proliferación de actividades encaminadas a "matar" el tiempo libre, o como diría Gianni Toti, nuestra vida misma.

PALABRAS CLAVE: florecimiento humano, tiempo libre, alienación, trabajo

According to the human flourishing approach, individuals can deploy all their capabilities and human needs through work. This paper debates the possibilities of attaining human flourishing within a society divided in classes, such as capitalism, given the alienated characteristics of work. It also questions the idea that free time can function as the space where human flourishing can be achieved, due to the increasing alienation it's being subjected to, which can be seen in the proliferation of activities oriented towards the "annihilation" of free time or, as Gianni Toti would say, of life itself.

KEY WORDS: human flourishing, free time, alienation, work 
Nadie aceptaría ser esclavo por dos horas; para ser aceptada, la esclavitud debe durar cada día el tiempo suficiente para quebrantar algo dentro del hombre.

Simone Weil, La condition ouvrière

E l elemento constitutivo del florecimiento humano ${ }^{1}$ lo define Julio Boltvinik como el "desarrollo de las capacidades y necesidades humanas, entendidas como una unidad interactiva del lado pasivo y el activo del ser humano" (véase el artículo de Boltvinik en este mismo número $)^{2}$. A partir del análisis de la esencia y de las necesidades humanas Boltvinik identifica las precondiciones (sociales e individuales) que deben cumplirse para abrir la posibilidad del florecimiento humano. Boltvinik reconoce que tanto la alienación como la duración de la jornada de trabajo (y la falta de su antítesis, el tiempo libre) representan limitaciones objetivas que los individuos deben superar como condiciones necesarias previas a la posibilidad de florecimiento humano.

De la propuesta de Boltvinik (2005) se deriva que en el capitalismo, a nivel individual y societal, la clase subordinada requiere ganar, al tiempo de trabajo, el tiempo libre necesario para alcanzar el florecimiento humano. La discusión en torno a la limitaciones objetivas para que se dé el florecimiento humano puede ampliarse, introduciendo la pregunta de si efectivamente en el capitalismo pueden darse tales condiciones sin modificar las relaciones sociales de producción ${ }^{3}$. Con este cuestionamiento en mente, desde diversas perspectivas, retomo algunos trabajos que abordan la cuestión de la jornada

\footnotetext{
${ }^{1}$ Este concepto proviene de la filosofía analítica y es similar al de autorrealización propuesto por Maslow (1943) en su famosa jerarquía de las necesidades humanas.

2 El lado activo se refiere a la capacidad del ser humano de hacer cosas, mientras que el pasivo alude a sus necesidades. Eentre ambos "lados" se establece una relación dialéctica, al existir en los seres humanos la necesidad de desarrollar sus capacidades.

3 Debe aclararse que el objeto de la tesis de Boltvinik, como él mismo lo precisa en la introducción a su voluminosa obra, no es el de los determinantes, sino el de los elementos constitutivos del florecimiento humano.
}

laboral y el tiempo libre. Especial atención merece el trabajo del sociólogo marxista italiano Gianni Toti (Tiempo libre y explotación capitalista, 1975), quien establece que la única posibilidad objetiva para alcanzar la unificación del tiempo de trabajo y del tiempo libre, unificación equiparable al florecimiento humano, es la eliminación de la sociedad dividida en clases, ya que en ésta la alienación no sólo se da durante el tiempo de trabajo, sino también durante el tiempo libre.

Boltvinik y Toti coinciden en que el florecimiento humano no será posible en cuanto no se satisfagan las necesidades humanas más básicas (que en términos de Maslow, 1943, serían las de mayor jerarquía o las de menor potencia: las que dominan al ser humano cuando todas las necesidades están insatisfechas). Coinciden también en que la alienación es un obstáculo al florecimiento humano (o a la unificación del tiempo de trabajo y el libre).

Para Boltvinik, el florecimiento humano se dará en la medida en que se supere la alienación (junto con la pobreza). No obstante, advierte que a pesar de que en la actualidad el tiempo libre se ha convertido en el espacio casi único para el florecimiento, éste puede terminar siendo desperdiciado en actividades con un alto grado de alienación (como ver la televisión), sin conducir al florecimiento. Sobre los dos principales obstáculos para lograr el florecimiento humano (la pobreza y la alienación), Boltvinik nos dice:

La pobreza económica es sólo el primer obstáculo a vencer para que ello [el florecimiento humano] sea posible. Pero es un obstáculo que la inmensa mayoría de los habitantes del planeta no ha superado hoy. Después hay muchos obstáculos más, el más importante de los cuales es la alienación. Si lo único que posee la inmensa mayoría de las personas del planeta, que es su propio cuerpo y mente, con las capacidades y conocimientos, pocos o muchos, que hayan podido desarrollar, lo tienen que vender para sobrevivir. Si lo único que posee la persona lo usa alguien más por ocho o más horas diarias, ¿qué es la persona? Si en ese uso que otro hace de sus capacidades humanas, la persona no se siente realizada, no siente sus fuerzas esenciales transformando al mundo y transformándose a sí misma; si sólo siente cansancio y tedio, si siente el producto del trabajo como algo ajeno y es, en efecto, ajeno, ya que pertenece al patrón, qué sentido tiene que la paga recibida sea suficiente para sobrevivir, si al día siguiente, y al año siguiente, será igual. Esto 
es lo que Marx llamó la alienación. La pobreza y la alienación son los dos obstáculos fundamentales para el florecimiento humano.

La esperanza de muchos seres humanos que viven para sobrevivir está fincada en el tiempo libre. Huyendo del trabajo que se hace para sobrevivir, piensan como Luis Buñuel cuando hacía las películas que llamó alimenticias, o como Kafka, que escribía en el tiempo libre que le dejaba un trabajo que odiaba, que en el tiempo libre podrán hacer lo que siempre han querido hacer o convertirse en lo que siempre han querido ser. La mayoría, sin embargo, termina desperdiciando ese valioso tiempo libre frente al televisor viendo programas chatarra que pauperizan su intelecto (Boltvinik, 2005: 419).

Toti, sin embargo, plantea que la sociedad dividida en clases (incluyendo al capitalismo) es el principal obstáculo para que el tiempo libre se transforme en un tiempo de libre creación. De acuerdo con el autor:

en la sociedad dividida en clases, la actividad de relación entre el hombre y la naturaleza se ha desdoblado trágicamente. El trabajo ha hecho al hombre dueño de las fuerzas naturales, se ha convertido en la fuente de su inspiración y de su dicha futura; al propio tiempo, lo ha hecho esclavo de sí, lo ha privado de sus fuerzas y de su tiempo (1975:281).

Más adelante sostiene que es sólo en el socialismo en el que:

El trabajo se deja prever como algo distinto a sí mismo, un trabajo que ya no es trabajo sino actividad creadora, que se transfiere siempre más en el tiempo de libertad, hasta identificarse totalmente con él. El trabajo, la ganancia, ya no constituyen del todo las medidas para la repartición de los bienes producidos colectivamente. La medida no es el trabajo sino el hombre. El hombre: final y verdadera medida de todas las cosas. El trabajo y el arte, las dos caras de Jano, se unifican en una sola fisonomía (1975: 281).

La diferencia fundamental en la discusión sobre los alcances del tiempo libre en el capitalismo entre ambos autores radica en que Boltvinik lo identifica como una precondición para el florecimiento humano, mientras que Toti lo precisa como un síntoma de la alienación del trabajo en el actual sistema de producción, que se manifiesta en una escisión de éste con el tiempo de trabajo. No

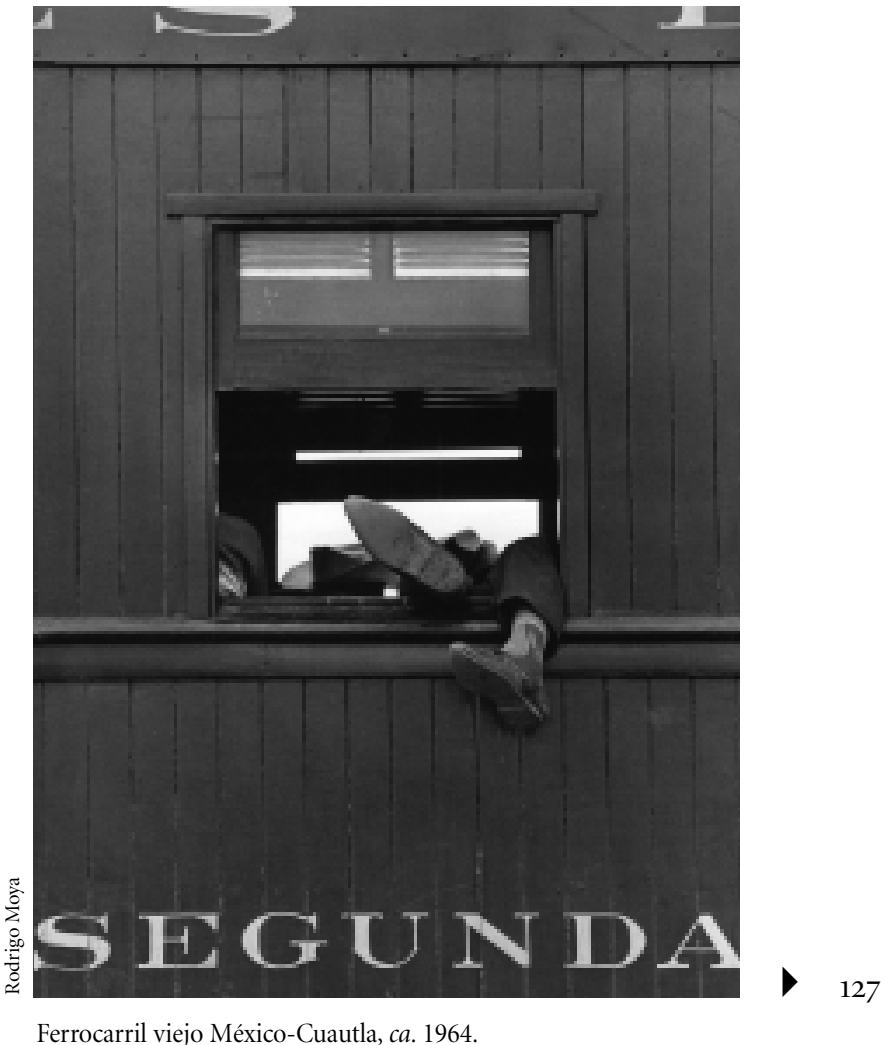

obstante, aunque este último autor considera que la unificación del tiempo de trabajo y el libre sólo será posible en el socialismo, reconoce que en el capitalismo existen "hombres cuyo trabajo es el fruto de su libre elección en un alto nivel intelectual — artistas, científicos, políticos[que] nunca se acogen al retiro y se mantienen en un trabajo durante toda la vida, diferenciando muy poco el trabajo del tiempo libre" (1975: 200). Estos individuos habrían alcanzado lo que Boltvinik llama florecimiento humano. Pero la existencia de éstos para Toti se presenta como una rareza, algo fuera de lo común.

La escasez de individuos que alcanzan el florecimiento humano también es señalada por Abraham Maslow, reconocido psicólogo estadounidense. En su jerarquía de necesidades humanas Maslow (1943: 382-383) afirma que, una vez satisfechas las de menor jerarquía, los individuos sienten la necesidad de "hacer lo que pueden y deben hacer, es decir, aparece la necesidad de autorreali- 
zación" 4 . Es entonces cuando "podemos esperar la mayor (y más sana) creatividad"5. Maslow también señala que en nuestra sociedad este tipo de personas son una excepción.

Por su parte, Sebastian De Grazia (1994), filósofo de Estados Unidos que analizó las formas que asume el tiempo libre en la sociedad estadounidense moderna, también habla de la existencia de una clase social minoritaria dedicada al ocio, entendido éste en su sentido filosófico clásico como la actividad de contemplación (es decir, el teorizar y el filosofar) y la de la música ${ }^{6}$.

Al contraponer la concepción occidental del tiempo libre frente a la griega de ocio, De Grazia hace notar que quienes disfrutan del ocio no son

aquellos de riqueza, posición o nacimiento, sino los que aman las ideas y la imaginación. En un siglo pueden ser científicos, en otro teólogos, cualquiera que sea la categoría, ésta les garantiza la libertad de jugar con sus mentes [...] Es un selecto y pequeño mundo de pensadores, artistas y músicos, que encuentran su felicidad en lo que hacen, que no pueden hacer otra cosa, su espíritu no los deja" (1994: 377).

${ }^{4}$ En el esquema de Maslow, la autorrealización es la necesidad humana de menor jerarquía (y la más alta, la más específicamente humana), la cual aparece sólo cuando se satisfacen las necesidades de mayor jerarquía (fisiológicas, de seguridad, de amor y de autoestima). El esquema de Maslow no aborda directamente la cuestión de la disponibilidad de tiempo para satisfacer las necesidades humanas. Sin embargo, habla de ello de manera marginal al enfatizar el efecto destructor que tiene en los menores de edad el moverse constantemente, el no vivir en un ambiente seguro, libre de miedo, ansiedad y caos, así como la necesidad de vivir estructuradamente con orden, límites, etc. Un menor abandonado por falta de tiempo tendrá seguramente serias dificultades para avanzar en la realización de necesidades de menor jerarquía y, por tanto, una menor posibilidad de alcanzar la autorrealización (o florecimiento humano).

${ }^{5}$ Maslow reconoce la existencia de casos en los que la jerarquía de necesidades no sigue el orden identificado por el autor. Por ejemplo, en las personas con creatividad innata puede que el impulso de la creatividad sea más importante que cualquier otro determinante. Su creatividad puede aparecer no como autorrealización motivada por la satisfacción de necesidades básicas, sino a pesar de la falta de satisfacción de éstas (Maslow, 1943: 387).

${ }^{6}$ De Grazia retoma la definición de Aristóteles sobre el ocio, el cual es concebido como la libertad de la necesidad de trabajar. El ocio era considerado por los griegos como un estado del ser en el que la actividad realizada es llevada a cabo por su propio fin (1994: 13-15). Las únicas dos actividades que eran consideradas constitutivas del ocio eran la contemplación (filosofar o teorizar) y la música. Para De Grazia, el ocio en su sentido clásico nos trae el beneficio de cultivar la mente libre mediante la creatividad, la verdad y la libertad (1994: 413).
De Grazia identifica una clase social que practica de manera rudimentaria el ocio en nuestra sociedad, la cual está constituida por los pintores, poetas, filósofos, etc., que uno puede encontrar en cada pueblo o ciudad. No obstante, si bien estas personas pueden tener la necesidad de ocio, "no llevan a cabo el ocio propiamente dicho, dado que viven bajo la sombra de la necesidad” (1994: 386). Es decir, para De Grazia también las personas deben estar libres de la necesidad (de trabajar para subsistir) para que puedan disfrutar del ocio (o florecimiento humano).

Con base en los diversos autores analizados hasta ahora nos podemos preguntar: ¿es acaso la escasez de individuos autorrealizados (o libres o que han logrado el florecimiento humano) una muestra de que no existen las condiciones socialmente generalizadas para que la mayoría de la sociedad llegue a este nivel de realización? ¿Hasta dónde el tiempo libre nos puede conducir al florecimiento humano? ¿Por qué el florecimiento humano no ha sido alcanzado por proporciones mayores de la población a pesar de la reducción de la extensión de la jornada laboral (y por tanto, de la ampliación de su antítesis, el tiempo libre)? Para contestar estos interrogantes, el presente artículo aborda la determinación de la duración de la jornada laboral en el capitalismo, incluyendo las luchas obreras que han tenido como resultado una mayor disponibilidad de tiempo libre y la resistencia y respuesta del capital a tal reducción. Asimismo, se analiza la forma cómo el capitalismo transforma la vida del trabajador, produciendo una escisión entre el tiempo de trabajo y el tiempo libre (diferencia poco presente en formas precapitalistas de producción $)^{7}$. Por otra parte analizaré cómo, dada la apropiación privada de los medios de producción y la alienación del trabajo, la fragmentación del proceso productivo conlleva a un desencanto por el trabajo en el obrero (o sensación de vacío), que se traslada al tiempo libre. Finalmente, discuto las barreras que se erigen en el capitalismo para limitar el florecimiento humano, aun en los casos en los que existen condiciones objetivas para que éste se dé.

\footnotetext{
${ }^{7}$ Posiblemente en el esclavismo se da más claramente la división entre trabajo manual y no manual; sin embargo, las personas no vivían la escisión propiamente dicha, ya que los esclavos dedicaban su vida al primero, mientras los hombres libres lo hacían al segundo.
} 


\section{LOS LÍMITES DE LA JORNADA DE TRABAJO}

Si “para la inmensa mayoría el tiempo libre aparece como la única oportunidad de realizar actividades libremente elegidas y creativas" (Boltvinik, 2005: 433) portante analizar el proceso histórico mediante el cual se establecen los límites de la jornada de trabajo y aparece el tiempo libre como una necesidad del trabajador en el capitalismo.

En los distintos modos de producción, basados en la obtención de la riqueza mediante la propiedad privada de los medios de producción, la clase dominante busca controlar el uso del tiempo de la clase subordinada, ya que es el trabajador el que produce para asegurar la reproducción de él mismo y de los dueños de los medios de producción. Así fue expresado por Marx cuando analiza el plustrabajo:

Dondequiera que una parte de la sociedad ejerce el monopolio de los medios de producción, el trabajador, libre o no, se ve obligado a añadir al tiempo de trabajo necesario para su propia subsistencia tiempo de trabajo excedentario y producir así los medios de subsistencia para el propietario de los medios de producción, ya sea propietario un aristócrata ateniense, un teocrático etrusco o civis romanus (ciudadano romano), el barón normando, el esclavista norteamericano, un bayordo valaco, el terrateniente moderno o el capitalista (1999 [1867]: 282).

Pero, ¿cuál es el límite de la jornada de trabajo? De acuerdo con Marx,

en el capitralismo de la naturaleza del intercambio mercantil (que se da cuando el trabajador vende su fuerza de trabajo al capitalista) no se desprende límite alguno de la jornada laboral, y por tanto límite alguno del plustrabajo. El capitalista, cuando procura prolongar lo más posible la jornada laboral y convertir, si puede una jornada en dos, reafirma su derecho en cuanto comprador. Por otra parte, la naturaleza específica de la mercancía vendida trae aparejado un límite

\footnotetext{
${ }^{8}$ Me parece importante volver a insistir en que este autor considera la existencia del tiempo libre como "una condición necesaria pero no suficiente (para el florecimiento). Una fracción mayoritaria de la población (también difícil de precisar) usa el tiempo libre disponible en actividades que prolongan la enajenación del trabajo de otra manera (como ver televisión comercial de baja calidad)" (Boltvinik, 2005: 433).
}

de consumo que de la misma hace el comprador, y el obrero reafirma su derecho como vendedor cuando procura reducir la jornada laboral a determinada magnitud normal (1999 [1867]: 282).

Aunque la jornada laboral nunca ha tenido una medida constante en suma, sino una medida variable que se mueve dentro de límites físicos, sociales y morales muy distintos según las diferentes condiciones, la obtención de plustrabajo se ha presentado muchas veces en formas "horribles" (como diría Marx) a lo largo de la historia. Uno de los ejemplos más extremos lo encontramos en las narraciones del historiador griego Diodoro Sículo sobre las condiciones de trabajo en las minas de oro en Egipto, Etiopía y Arabia durante el esclavismo:

$[\ldots]$ no se puede contemplar a esos infelices $[\ldots]$ que ni siquiera pueden asear sus cuerpos o cubrir su desnudez, sin dolerse de su trágico destino. Pues allí no tienen ninguna indulgencia ni miramiento por los enfermos, los enclenques, los ancianos, por la endeblez femenil. Obligados a golpes, todos deben continuar trabajando hasta que la muerte pone término a sus tormentos y su miseria (cit. en Marx, 1999 [1867]: 283).

La generalización de las relaciones capitalistas de producción conllevó la imposición de jornadas laborales extremas, en las que se llegó literalmente a la apropiación de todo el tiempo de vida de los trabajadores. Al respecto, E. P. Thompson describe la jornada laboral prevaleciente en la Inglaterra del siglo XVIII, que aparece en los Anales de la Agricultura (de 1796):

[...] ellos [los trabajadores] deben trabajar de cinco de la mañana hasta las siete-ocho de la noche, desde mediados de marzo hasta mediados de septiembre - y de aquí en adelante desde el despertar del día hasta la noche, con dos medias horas para beber, una hora para cenar y (sólo en el verano) media hora para dormir: en cualquier caso, por cada media hora de ausencia se descontará un penique (1967: 61)9.

\footnotetext{
${ }^{9}$ Sin embargo, esta forma de explotación no era exclusiva de este tiempo. Toti cita el primer Statute of Labourers, de la Inglaterra de Eduardo III (fechado en 1349), en el que se establecía que de marzo a septiembre los trabajadores agrícolas y artesanos tenía un horario de las cinco de la mañana hasta alrededor de las siete y ocho de la noche, con una hora
} 


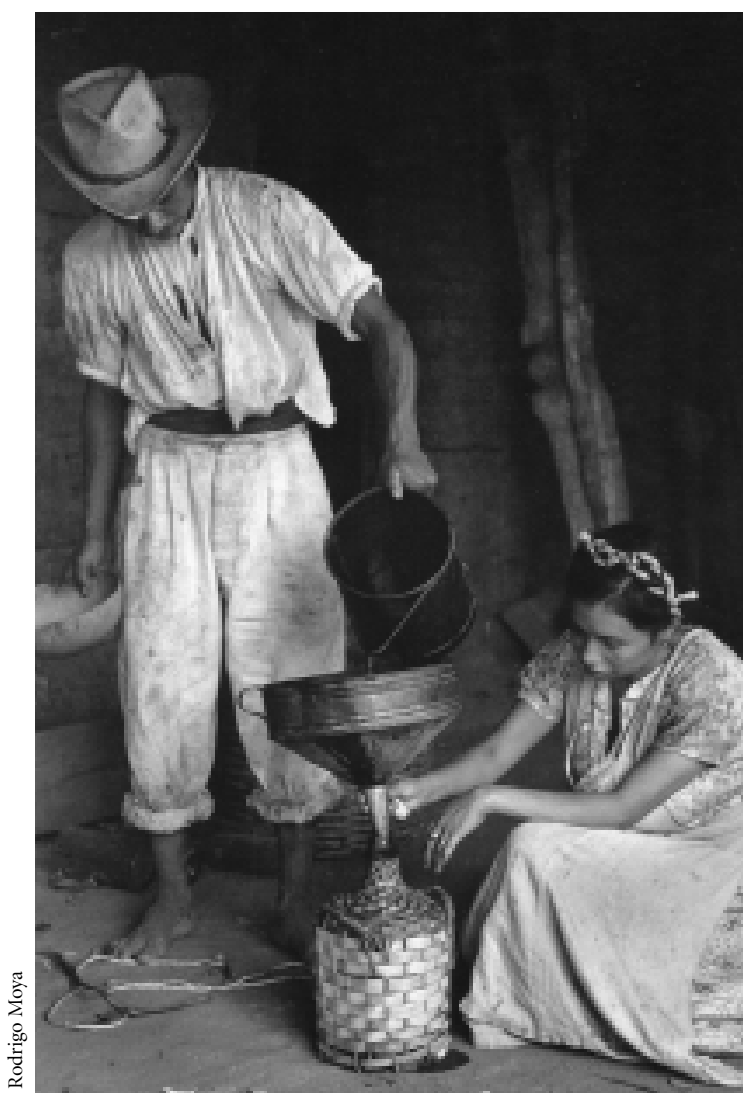

Minas, Oaxaca, 1960.

No obstante, a lo largo del capitalismo los dueños de los medios de producción enfrentaron la resistencia de los trabajadores a dedicarse de manera exclusiva al trabajo asalariado. Desde los albores de este modo de producción, los empleadores tenían dificultades para adueñarse de toda la semana del obrero, así como de toda la fuerza laboral. Al respecto, Thompson cita el Commercial \& Agricultural Magazine de 1800 para mostrar cómo los empleadores de aquel tiempo se quejaban públicamente de

de descanso para el desayuno, hora y media para el almuerzo y media hora para la merienda de las cuatro. Por otra parte, Marx describe cómo, cuando se aprueba la reducción de la jornada de trabajo a diez horas, los capitales eliminaban de la cuenta neta de tiempo dedicado al trabajo el destinado a la alimentación y el descanso, derechos que eran reconocidos cuando la jornada legal era de doce horas diarias (1999 [1867]: 345). la escasa mano de obra dispuesta a emplearse de "manera regular", es decir, dispuesta a dedicar "dos terceras partes de su tiempo" al trabajo asalariado (1967: 76-77). En cuanto a la resistencia de los pequeños propietarios, los empleadores manifestaban:

cuando un trabajador se convierte en poseedor de un pedazo de tierra mayor al que puede cultivar con su familia por las tardes-noches [...] el agricultor no puede ya más depender de él para trabajar constantemente.

Asimismo, se criticaba ferozmente la "ineficiencia y la pérdida de tiempo" de los granjeros, que también se negaban a emplearse en aquella época:

[...] si les ofreces trabajar, ellos te dirán que deben cuidar de sus ovejas, cortar el grano, llevar a sus vacas a pastar; dirán que deben llevar a sus caballos a poner herraduras, que lo tienen que llevar a una carrera de caballos o a un partido de criket (Arbuthnot) (todas las citas en Thompson, 1967: 76-77).

Esta poca disposición a emplearse de tiempo "completo" se extendió hasta el siglo XIX, y en cierta medida prevaleció entre los trabajadores rurales que se negaban a emplearse de "manera regular" a cambio de un salario.

Durante los siglos XVII y XVIII, el capital enfrentó no sólo la resistencia de los trabajadores a emplearse de manera regular, sino también su apego tenaz a sus tradiciones y fiestas religiosas que se extendían durante una buena parte del año ${ }^{10}$.

La posibilidad de no emplearse a tiempo completo pudo ser posible gracias a que en los albores del capitalismo los trabajadores (tanto agrícolas como industriales) podían vivir una semana completa con lo obtenido en cuatro días de trabajo (Marx, 1999 [1867]: 333). De acuerdo con E. P. Thompson, sólo los trabajadores agrícolas o sirvientes que no tenían derechos comunes o tierra estaban sujetos a una disciplina de trabajo intensa (1967: 77).

\footnotetext{
${ }^{10}$ Por ejemplo, según Paul Lafargue (yerno de Marx), antes de la Revolución francesa se garantizaban a los obreros noventa días (sic) de descanso al año, o sea, cincuenta domingos y treinta días de fiesta en los que se prohibía trabajar (El derecho a la pereza, citado en Toti, 1975: 156).
} 
Ante la resistencia de los trabajadores a emplearse seis días a la semana se implementaron diversas medidas para someterlos. Por ejemplo, Marx (1999 [1867]: 331) cita a Postlethway (muy famoso en su tiempo, autor de un diccionario de comercio), quien manifiesta su desacuerdo con las tácticas de los políticos ingleses que, con tal de obligar a los artesanos y obreros manufactureros a emplearse los seis días de la semana, aumentaban los impuestos, el precio de los medios de subsistencia o bien bajaban los salarios.

Fue a finales del siglo XVIII y principios del XIX "que el capital logró adueñarse de toda la semana del obrero" mediante pagos semanales (excepto el domingo, ya que era considerado día sagrado). De acuerdo con Marx, "tuvieron que pasar siglos para que el trabajador libre se adaptara voluntariamente, como consecuencia del modo capitalista de producción —es decir, que fuera obligado socialmente - a vender, por el precio de sus medios de subsistencia, todo el periodo activo de su vida, su capacidad misma de trabajo: a vender su primogenitura por un plato de lentejas" (El capital, cit. en Toti, 1975: 19).

Además de volverse dependiente de un salario, la fuerza de trabajo, acostumbrada a guiarse por los tiempos de la naturaleza, tuvo que ser obligada a ajustarse a los tiempos de la producción mecanizada, a concentrarse durante un número determinado de horas en un local cerrado y someterse al ritmo de la máquina. La nueva sociedad se caracterizaba por

la introducción de sistemas de avasallamiento y de explotación que ni siquiera el Medioevo había conocido, por lo menos en aquellas proporciones. Nunca fue tan envilecida la dignidad humana como en aquellas primeras décadas, nunca fueron impuestas y practicadas formas de trabajo tan brutales como en los "talleres del sudor" (así se denominaron porque los locales carecían de aire, de luz y de espacio) que proliferaron entonces, y en los que las jornadas laborales oscilaban de ochenta a cien horas a la semana. El tiempo libre era el tiempo para dormir (cuatro, cinco o seis horas máximo), para comer e ir y venir de la fábrica [...]. La reducción de los costos de producción [...] se obtenía desfalcando los salarios y rapiñando tiempo humano, aumentando las horas de trabajo hasta el límite físico constituido por la necesidad de dejar a la máquina humana el tiempo de reintegrar su propia fuerza. El capitalismo en expansión se alimentaba del tiempo, se desarrollaba con el tiempo de trabajo y su hambre de tiempo aumentaba en lugar de disminuir (Toti, 1975: 24-25).

El progreso técnico, por su parte, agudizaba las condiciones de explotación. A la par de que el capital se adueñaba de la vida misma del obrero, se generalizaba el uso de máquinas, plasmándose de manera contundente la codicia del capital por apropiarse progresivamente del tiempo vivo. Por ejemplo, la iluminación con gas permitió aumentar, sobre todo en el invierno, la duración de la jornada de trabajo. El advenimiento de la máquina de vapor eliminó el paro obligado durante la sequía en las fábricas dependientes del motor hidráulico. De acuerdo con Marx, a partir del nacimiento de la gran industria, en el último tercio del siglo XVIII, tuvo lugar una violenta y desmesurada arremetida del capital para extender la jornada laboral. Afirmaba: "todas las barreras erigidas por la costumbre y la naturaleza, por la edad y el sexo, por el día y la noche, saltaron en pedazos" (1999 [1867]: 335).

La mecanización del proceso productivo se presenta en el sistema capitalista como un desarrollo que busca, en parte, aligerar la carga de trabajo; sin embargo, en verdad está guiada más por la lógica de extracción de plustrabajo. Para Marx, en la sociedad basada en la propiedad privada de los medios de producción,

el tiempo de trabajo como medida de la riqueza hace de la riqueza misma algo basado en la miseria y en el tiempo disponible que existe en oposición al tiempo de plustrabajo; $\mathrm{y}$, a través de ello, considera todo el tiempo de un individuo como tiempo de trabajo, degradándolo, por consiguiente, a mero trabajador. Por esta razón, las máquinas más perfeccionadas obligan ahora al trabajador a laborar por más tiempo que el salvaje, o más que lo que éste trabajaba con los instrumentos más simples y toscos (Marx cit. en Toti, 1975: 270-1, cursivas originales en el texto).

Por otra parte, Marx narra en El capital cómo mujeres, hombres y niños por igual eran sometidos a prolongadas jornadas laborales, tanto en horarios matutinos como nocturnos, lo que desembocó en luchas obreras que presionaron por la reducción de la jornada laboral.

Pero además, en su avidez por el trabajo vivo, el capitalismo instrumentó mecanismos para domesticar y utilizar a la fuerza de trabajo desde la niñez. El capitalismo, 
afirma Toti, estaba hambriento de tiempo de trabajo, no sólo de manera genérica, sino de tiempo joven. Al respecto E. P. Thompson (1967: 84) narra cómo la escuela se constituyó en una de las principales instituciones para "acostumbrar" a la fuerza de trabajo a los nuevos ritmos industriales. Cita la recomendación de un empresario de nombre William Temple (considerado un gran benefactor en su tiempo) sobre la conveniencia de que los niños pobres fueran enviados a las "casas de trabajo" desde la edad de cuatro años. Ahí debían recibir educación dos horas diarias y ser empleados (durante el resto de una jornada laboral "normal" en la manufactura). Con ello se lograría que a la edad de seis o siete años, los menores se hubiesen "habituado, por no decir naturalizado, al Trabajo y la Fatiga"11 (mayúsculas en el original).

En poco tiempo los niños se volvieron más valiosos que los adultos. La primera ventaja fue que eran más baratos, la segunda, su adaptabilidad a la disciplina de las fábricas. Los talleres del sudor que proliferaron en la revolución industrial empleaban a niños ${ }^{12}$. De esta manera, de su trabajo en los cultivos de algodón pasaron a las minas, de la elaboración de cerámica a las cerilleras. Marx narra cómo la legislación británica del siglo XIX dejó por décadas vacíos que permitían emplear por hasta doce horas diarias a jóvenes y niños (1999 [1867]: 338-346). Por lo general, las jornadas infantiles eran más restrictivas que la de los jóvenes, pero los capitalistas siempre busca-

${ }^{11}$ Los capitalistas no se limitaron a la búsqueda de mecanismos salvajes de "domesticación" de los niños al trabajo en las fábricas. En el trabajo publicado por Paul Lafargue (El derecho a la pereza) se cita un reporte al Primer Congreso de la Beneficencia que tuvo lugar en Bruselas en 1857, en el que un rico manufacturero afirmaba: "Nosotros hemos introducido algunos medios de distracción para los niños. Les enseñamos a cantar durante el trabajo: eso los distrae y les hace soportar válidamente las doce horas de trabajo que deben emplear para conseguirse los medios de subsistencia" (cit. por Toti, 1975: 154).

${ }^{12} \mathrm{Al}$ respecto, Toti relata las atrocidades cometidas contra los niños en esos talleres. Una encuesta realizada en las fábricas inglesas en 1831 sostiene que en algunas de éstas, "pocas veces pasa una hora sin que se oigan los gritos de los niños golpeados. Y a menudo sucede que sean los propios padres los que pegan a sus hijos para evitarles castigos todavía más brutales. Los muchachos son golpeados con el bill roller, una barra de hierro pesada, y es frecuente el caso de muchachos que se deslizan muertos de sueño bajo las máquinas, quedando horriblemente mutilados. Para mantener despiertos a los muchachos durante las largas horas de trabajo se les da con el látigo. El látigo es parte corriente de los instrumentos esenciales para el desarrollo de la producción" (1975: 26). ban formas de emplear la fuerza laboral desde temprana edad. Marx afirma de manera irónica: "según la antropología capitalista, la edad infantil termina a los diez años, o cuando más, a los once." Las lagunas legislativas eran aprovechadas por los fabricantes deseosos "de hacer trabajar su maquinaria más de diez horas”, empleando a niños desde los ocho años de edad, haciéndolos laborar hasta las 8:30 de la noche (1999 [1867]: 338).

Cuando De Grazia analiza este proceso nos dice: "al final el Parlamento los rescató. Al final, pero para entonces la industria había encontrado su fuerza de trabajo, y la siguiente generación había sido propiamente educada en los hábitos del trabajo" (1994: 200)13.

La ingente explotación de la fuerza de trabajo en general provocó luchas obreras que proclamaban no sólo una mejor remuneración, sino una humanización de las condiciones de trabajo, incluyendo la reducción de la jornada laboral. Nace así, en el obrero capitalista, la necesidad de contar con un tiempo libre, un tiempo para él.

\section{LUCHAS OBRERAS POR LA REDUCCIÓN DE LA JORNADA LABORAL}

Las primeras agitaciones obreras por el tiempo libre se mezclaron con reivindicaciones salariales. Por mucho tiempo la necesidad de un trabajo de cualquier duración dominó cualquier otra exigencia. Fue en 1791 que surgieron las primeras luchas obreras organizadas en Filadelfia, Estados Unidos, para exigir el tiempo libre. Los albañiles de esa ciudad denunciaban que los patrones trataban de reducir el salario, además de obligarlos a trabajar por el entero curso de las más largas jornadas de verano, sin recompensa inmediata. Sus exigencias con-

\footnotetext{
${ }^{13}$ No fue sino hasta 1834 que se prohibió el trabajo de los menores de nueve años (con excepción de los talleres de seda que 'requerían' las pequeñas manos ágiles infantiles) y se limitó la jornada laboral a nueve horas para los niños que tenían entre nueve y trece años de edad, y a doce horas para los de 14 a 18 años. En 1933 se estableció en Gran Bretaña la edad de doce años como la mínima para trabajar. En la actualidad es de 13 años en ese país y de 14 en el nuestro. Cabe resaltar que en el capítulo VIII del tomo I de El capital, Marx narra el infame uso de la fuerza de trabajo en los siglos XVIII y XIX, así como la resistencia de los capitalistas a dejar de hacerlo.
} 
sistían en reducir el horario de trabajo y ser retribuidos por el trabajo extraordinario (Toti, 1975: 21-22). En Europa, las organizaciones gremiales que exigían como una de sus principales reivindicaciones una reducción de la jornada de trabajo se enfrentaron no sólo con los dueños de las empresas (como sucedía en Estados Unidos) sino también con Estados nacionales que combatían directamente los derechos de los trabajadores ${ }^{14}$.

No fue sino hasta el $1^{\circ}$ de mayo de 1848 que entra en vigor la ley de diez horas en Inglaterra (Marx, 1999 [1867]: 344). Todavía a finales del siglo XIX, aún con horarios muy prolongados, la lucha obrera por el tiempo libre tenía como objetivo general lograr la jornada de diez horas (aparte comidas) por día. No obstante, se iba creando en el obrero colectivo una conciencia de la necesidad de limitarla a ocho horas ${ }^{15}$, que se generalizó en el mundo occidental en las primeras décadas del siglo XX.

Aun así, a lo largo del siglo pasado continuaron las luchas reivindicativas por una mayor reducción de la jornada laboral ${ }^{16}$. A pesar de ello, existen grandes diferencias en la duración de la jornada de trabajo en el mundo. Pre-

\footnotetext{
14 Una muestra de cómo los Estados-naciones realizaban acciones a favor del capital se ejemplifica con la acción del Estado prusiano, que abolió mediante una ley, en 1783, la costumbre del "lunes azul" (San Lunes, como se conoce en México), que era considerado por muchos gremios de trabajadores alemanes como día de descanso. En Francia, después de la abolición del régimen feudal, Bonaparte toma las primeras medidas del Estado burgués moderno para mantener la sumisión de los trabajadores e impedir la formación de coaliciones obreras, discutir las condiciones de trabajo, etc. Por otra parte, en 1834 el parlamento inglés aprobó una enmienda a la ley de pobres en la que se establecía el trabajo forzado para los pobres y, además, privó de los derechos electorales a las personas que eran objeto de la caridad pública (Toti, 1975: 22, 29-30 y 39).

15 Por ejemplo, en un opúsculo titulado La nueva ley sobre las fábricas, de 1897, Lenin planteaba como reivindicación obrera la jornada de ocho horas: "Es necesario que el obrero trabaje al máximo ocho horas diarias para tener así el tiempo de descansar, instruirse, disfrutar de sus derechos de hombre, de miembro de la familia y de ciudadano" (cit. en Toti, 1975: 83-84).

${ }^{16}$ De Grazia pone en duda la idea de que los trabajadores contemporáneos gocen de una mayor disponibilidad de tiempo libre que los trabajadores de mediados del siglo XIX, a pesar de que los primeros tengan jornadas laborales más cortas. De acuerdo con este autor, si consideramos el tiempo que nos toma ahora realizar las actividades fuera del trabajo (pero relacionadas con éste), como el transporte, o bien el hecho de que un mayor número de mujeres participe en el mercado laboral, la cantidad de tiempo dedicado por la sociedad a estas actividades es casi la misma que en el pasado (1994: cap. III).
}

valecen formas salvajes de explotación, sobre todo en países pobres, mientras que en los más desarrollados los promedios han bajado significativamente. Por ejemplo, en Estados Unidos, Japón e Inglaterra, el promedio de horas trabajadas por ocupado era, en 2004, de un poco más de 40 a la semana, y en algunos países europeos, incluyendo ex socialistas (entre otros, Bélgica, España, Austria, Suecia, Suiza, Bulgaria, Lituania, Ucrania y Estonia, etc.), y Australia, el promedio era de entre 30 y 35 horas. En cambio, en países menos desarrollados como Brasil, Colombia, Costa Rica, Croacia, y algunos otros asiáticos más desarrollados (Hong Kong, que no es un país propiamente dicho, y Singapur) el promedio de la jornada laboral oscila de 42 a 48 horas a la semana, y es posible encontrar datos aún más extremos, como el de Egipto, que reporta 56 horas trabajadas en promedio a la semana ${ }^{17}$.

Algunos otros estudios han mostrado que en ciertas ramas de actividad económica siguen prevaleciendo jornadas laborales extremas, sobre todo en países pobres. Un estudio de Oxfam (2004), que analiza las condiciones laborales de las mujeres en grandes cadenas comercializadoras, denuncia que $75 \%$ de las mujeres que trabaja en el sector agrícola en Chile tienen contratos temporales y jornadas de más de 60 horas a la semana en los periodos de cosecha. No obstante, una de cada tres de ellas gana menos del salario mínimo. Asimismo, en la provincia china de Guangdong, una de las áreas industriales de mayor crecimiento en el mundo, las mujeres tienen que trabajar cerca de 35 horas extras a la semana, además de las 48 horas de la jornada laboral legal: 50\% de ellas no tiene contrato por escrito y $90 \%$ no tiene seguridad social.

Por otra parte, a pesar de que importantes sectores laborales gocen de una jornada laboral corta y, por tanto, de mayor disponibilidad de tiempo libre, se sigue presentando en muchos trabajadores una "resistencia a aceptar alegremente la explotación”. Toti argumenta que este tema es de interés para el capital, en tanto se ha comprobado que la eficiencia en el trabajo aumenta si la satisfacción del trabajador en su espacio laboral es mayor ${ }^{18}$.

\footnotetext{
${ }^{17}$ Datos provenientes del Yearly Data, 2004, Organización Internacional del Trabajo (página web).

${ }^{18}$ No es casual entonces que a la par de que se desarrollaba la lucha
} 
Podemos entonces adelantar que, si bien la reducción de la jornada laboral a límites normales y moralmente aceptables constituye un importante avance de la lucha de los trabajadores, el sentimiento de aburrimiento y desinterés prevalece en la medida en que la naturaleza de la explotación y la alienación continúa dominando las relaciones sociales de producción. En la siguiente sección analizo cómo ha sido explicado el surgimiento del sentimiento de "descontento" laboral en el obrero capitalista.

\section{LA ESCISIÓN ENTRE VIDAY TRABAJO}

El sentimiento de insatisfacción respecto al trabajo en el sistema capitalista ha sido asociado a las diversas transformaciones en la organización del trabajo y en las relaciones sociales que caracterizan a este modo de producción. De acuerdo con E. P. Thompson (1967: 61), con la generalización de las relaciones sociales capitalistas de producción el trabajador experimenta (objetiva y subjetivamente) una escisión entre la "vida" y el "trabajo". La noción (y medición) del tiempo presente en la psique del trabajador en contextos en los que las diferentes situaciones de trabajo se relacionan con los ritmos "naturales" ha sido descrita como 'orientación por tarea' (taskorientation). Trabajar del amanecer al anochecer aparece como "natural" en una comunidad agrícola, especialmente en los meses de cosecha. En las comunidades primitivas la medición del tiempo estaba comúnmente relacionada con el ciclo de trabajo y de las actividades domésticas (Thompson, 1967: 58). El patrón de trabajo era uno de alternancia entre periodos de intenso trabajo y desocupación, pero en cualquier momento el hombre mantenía el control de su propia vida laboral (working life).

Una vez generalizadas las relaciones sociales de explotación en el capitalismo, es decir, la compra-venta de la

obrera, desde finales del siglo XIX se iniciaran en Inglaterra las primeras investigaciones en torno al efecto en la productividad de la reducción de la jornada de trabajo. Se concluyó que a menudo esta reducción disminuía la frecuencia de los infortunios, las enfermedades y las ausencias, y se demostró que el factor humano es importante, como diría Toti: ¡vaya descubrimiento! (1975: 159). fuerza de trabajo, se produce un cambio en la apreciación del tiempo entre el empleador y el empleado:

Tan pronto como se contratan empleados (actual hands), se marca el cambio entre la orientación del tiempo por tarea (task-orientation) hacia el trabajo cronometrado [...] Aquellos que son contratados experimentan una distinción entre el tiempo de su empleador y su "propio" tiempo. Y el empleador debe usar el tiempo de sus trabajadores, y velar porque no sea desperdiciado: no es ya la tarea en sí misma la dominante, sino el valor del tiempo, traducido en dinero. El tiempo se vuelve ahora moneda de cambio: no se 'pasa' sino que se gasta (Thompson, 1967: 61, cursivas añadidas).

Podemos decir entonces que el trabajador pierde el control de su vida laboral que ahora le pertenece al capital ${ }^{19}$.

Esta apropiación de la vida laboral del obrero se conjugó con una férrea disciplina en el trabajo. El cuidado del tiempo en el trabajo pagado depende, en gran medida, de la necesidad de sincronizar el trabajo. Pero en tanto que la industria manufacturera seguía dominada por la producción doméstica o en pequeños talleres, sin una intrincada subdivisión del proceso, el grado de sincronización demandado era menor, y prevalecía la orientación de las actividades de acuerdo con las tareas. Pero como bien señala Thompson, si consideramos la irregularidad en los ritmos de trabajo en las sociedades precapitalistas, podremos entender tanto la severidad de las doctrinas mercantilistas como la de la necesidad de bajar los salarios como una medida preventiva contra la holgazanería (idleness), así como que no haya sido sino hasta la segunda mitad del siglo XVIII que los incentivos salariales capitalistas "normales" empezaran a ser ampliamente efectivos (1967: 70-71). Otra de las medidas para obligar a la fuerza de trabajo a someterse a los ritmos del reloj fue la puesta en marcha, por parte de algunos propietarios pioneros de la industria manufacturera a gran escala, de algo equivalente a un código penal y civil basado en el control del tiempo (retardos, horas de comida, de descanso, etc.) (ibid.: 81).

\footnotetext{
${ }^{19}$ En la jerga marxista, este proceso se conoce como subsunción formal y real del trabajo al capital.
} 
Para mostrar la severidad del cambio en la sensación del tiempo a que fueron sometidos los trabajadores, E. P. Thompson hace notar algunas características de la noción y medición del tiempo por tarea y su contraste con el "tiempo cronometrado": 1) de acuerdo con algunos estudios (citados por el autor) existe una sensación más humanamente asimilable en la primera noción de tiempo que la que está dominada por el trabajo cronometrado; 2) en una comunidad en la que predomina la orientación por tarea es común tener una menor distinción entre "trabajo" y "vida" y; 3) para el hombre acostumbrado al trabajo cronometrado con reloj, el trabajo orientado por tarea aparece como una pérdida de tiempo (1967: 60)20.

Además de la escisión entre vida y trabajo, De Grazia observa que la generalización de la producción en fábricas y del uso del reloje ${ }^{21}$ redujo el ámbito de elección de la organización de la vida, así como el de las posibilidades de los individuos de socializar (1994: 59). Lo anterior lo ejemplifica describiendo el tipo de vida que llevaban los artesanos que realizaban la producción de mercancías en pequeños talleres, a inicios del capitalismo. Un artesano que producía zapatos podía salir libremente de su taller para ver pasar una procesión, tener a su familia alrededor, tomar una cerveza con el amigo que pasa y regresar más tarde para terminar su trabajo, o bien lo dejaba para el día siguiente. Los zapatos podían esperar; la máquina, en cambio, no puede apagarse.

${ }^{20}$ De Grazia sostiene que de la profunda transformación en los ritmos de trabajo impuestos, no sólo por la maquinaria automatizada sino también por el uso de reloj, ha provocado que en la actualidad veamos el tiempo de reloj como real. De acuerdo con el autor, a lo que llamamos tiempo no es más que el movimiento sincronizado de los relojes. Nos recuerda que existen diversas imágenes o concepciones del tiempo: 1) la lineal, asociada a la concepción moderna del tiempo, en la que éste no se repite, sino que es marcado por el tic del reloj en una línea recta, que va de $t$ a $t 1$ en un continuo; 2) la concepción circular, con eternos retornos, que es biológica más que mecánica; 3 ) la impresionística, es decir, aquella en la que se considera que las actividades rutinarias no toman tiempo, sólo los instantes vívidos, periodos excitantes, eventos importantes dejan la impresión de tiempo o duración; 4) la que carece de sistema de tiempo, en relación con comunidades que ni siquiera tienen una palabra o verbo que designe al tiempo, por ejemplo, la tribu hopi, que sólo tiene expresiones tales como más temprano o más tarde.

${ }^{21}$ Es importante resaltar que De Grazia no utiliza la terminología marxista ni se refiere al modo de producción capitalista. En su análisis menciona el cambio de vida experimentado a partir de la generalización de la producción mecanizada y del uso del reloj en todos los ámbitos humanos.

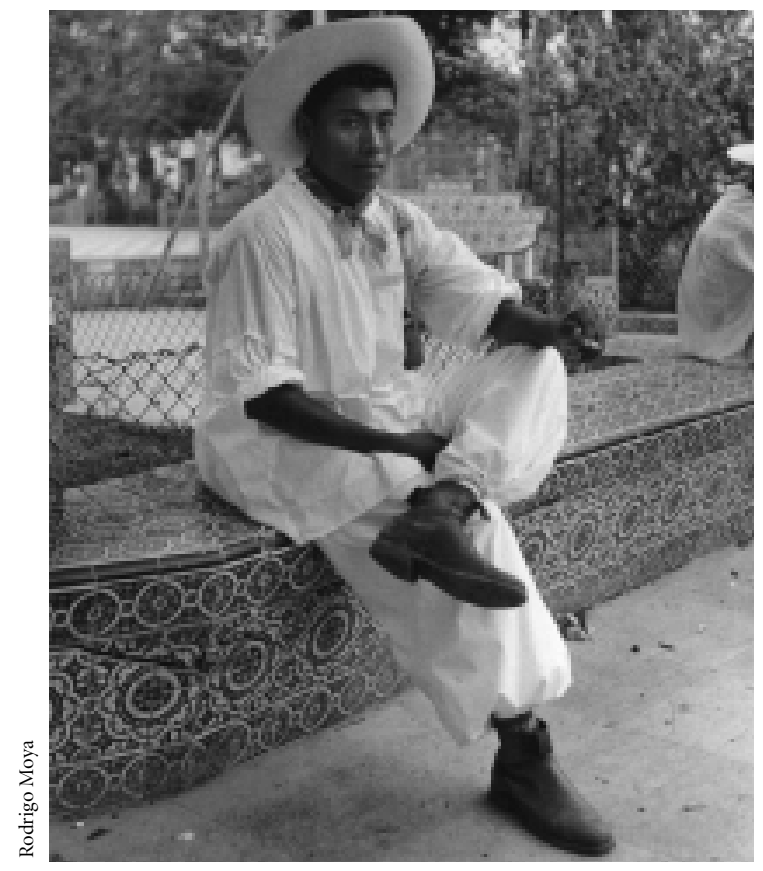

Papantla, Veracruz, ca. 1956.

De Grazia argumenta que la producción en serie trasladó a hombres, mujeres y niños de la libertad de los talleres y casas y los puso bajo los techos de las fábricas, cronometrando sus movimientos de acuerdo con los ritmos de las máquinas. La amistad, la charla y el coqueteo quedaron prohibidos en el trabajo, porque interfieren con los ritmos de las máquinas. El resultado fue el debilitamiento de la socialización ${ }^{22}$ y la eliminación de la posibilidad de que los individuos elijan libremente su actividad en cada instante de su vida.

Como hemos visto, la adaptación del trabajador a las relaciones sociales y formas de producción capitalista implicó un cambio en la apreciación y organización del tiempo. Su trabajo dejó de estar entrelazado con su vida. Su vida y su trabajo se desarrollan ahora en temporalidades distintas. Por tanto, el ser humano se escinde.

\footnotetext{
22 Éste es uno de los aspectos que, desde mi punto de vista, pueden llevar al sentimiento de soledad experimentado en sociedades mo-
} dernas. 
Otro de los grandes cambios a los que condujo la implantación de la forma capitalista de producción fue la reducción del ámbito de elección de las actividades a ser realizadas por los individuos, al estar sujeta la vida del trabajador a la máquina. Pero también se redujo el ámbito de la socialización, base de toda organización social.

Este último punto es de vital importancia si consideramos que los aspectos más básicos del comportamiento humano requieren de la disponibilidad de tiempo de los adultos para enseñar y transmitir normas éticas, morales, sociales y de uso de los objetos producidos por el hombre. La importancia de dicha transmisión la pone de relieve Márkus cuando señala que

las capacidades y las necesidades humanas desarrolladas en el pasado se encuentran ya, como hadas madrinas, en su forma objetivada, a la cabecera de su cuna, en un mundo en el cual los resultados de toda la precedente evolución social están ya a su disposición en forma material, le es posible empezar su desarrollo no en la incoación del primer principio, sino en el punto en que las generaciones anteriores lo han dejado (1985: 22).

Sin embargo, hace referencia a la necesidad de que los hombres desarrollen "en sí mismos —en alguna medi$\mathrm{da}$ — las cualidades humanas específicas que permiten el uso 'adecuado' de los objetos del trabajo". Este desarrollo requiere de la socialización del conocimiento de generación a generación ${ }^{23}$. Igualmente importante son las normas sociales del empleo de los objetos, ya que mientras que las de uso son técnicas, las sociales permiten, demandan o prohiben prácticas específicas dependiendo del sujeto o de la circunstancia ${ }^{24}$.

\footnotetext{
${ }^{23}$ En una entrevista que realicé recientemente a una educadora de preescolar en la ciudad de México, ella manifestó el atraso con el que se incorporan algunos miembros de las nuevas generaciones. Señaló, por ejemplo, niños mayores de tres años que no saben hacer uso de vasos o tazas para beber líquidos, o bien que siguen utilizando pañal dado que no han recibido atención en sus hogares para desarrollar estas capacidades elementales.

${ }^{24}$ En su lectura sobre la esencia y las necesidades humanas en György Márkus, Boltvinik (2005) ejemplifica la existencia de normas sociales de la siguiente manera: "mientras que la regla implícita de uso de un cigarrillo es que debe encenderse con fuego y el humo debe ser aspirado, etc., la norma social de su empleo prohibe fumar a los menores y a todos en ciertos lugares".
}

\section{DIVISIÓNY ALIENACIÓN DEL TRABAJO}

En el capitalismo la división técnica del trabajo aparece como otra fuente de insatisfacción laboral. Retomando a Marx y Márkus, Boltvinik presenta esta insatisfacción como resultado de la fragmentación de las diversas operaciones requeridas para producir un valor de uso, lo que arranca de las manos del artesano la visión y el control del proceso de producción en su conjunto. La importancia que tiene para el hombre la visión de conjunto de la producción, en un sentido humano, queda claramente explicitada por Marx en el siguiente pasaje:

Concebimos el trabajo bajo una forma en la cual pertenece exclusivamente al hombre [...] Una araña ejecuta operaciones que recuerdan las del tejedor, y una abeja avergonzaría, por la construcción de las celdillas de un panal, a más de un maestro albañil. Pero lo que distingue ventajosamente al peor maestro albañil de la mejor abeja es que el primero ha modelado la celdilla en su cabeza antes de construirla en la cera. Al consumarse el proceso de trabajo surge un resultado que antes del comienzo de aquél ya existía en la imaginación del obrero, o sea, idealmente [...] Además de esforzar los órganos a que trabajen, se requiere del obrero, durante todo el transcurso del trabajo, la voluntad orientada a un fin, la cual se manifiesta como atención. Y tanto más se requiere esa atención cuanto menos atrayente sea para el obrero dicho trabajo, por su propio contenido y la forma y manera de su ejecución, cuanto menos, pues, disfrute el obrero de dicho trabajo como de un juego de sus propias fuerzas físicas y espirituales (Marx, 1999 [1867]: 216).

Sin embargo, en el capitalismo, el obrero individual pierde la posibilidad de orientar su voluntad a un fin. Este cambio empieza en el capitalismo con la producción simple de manufacturas. De acuerdo con Marx, en esta etapa muchos artesanos (con los mismos oficios o con oficios diversos, pero requeridos para la producción final de un valor de uso, por ejemplo, una carreta) eran puestos a trabajar simultáneamente en los talleres (1999 [1867]: 409-411). Al requerir una cantidad mayor de mercancías, por unidad de tiempo ${ }^{25}$, los dueños del ca-

\footnotetext{
${ }^{25}$ Esta necesidad de mayor producción puede responder a la búsqueda
} 
pital notaron la conveniencia de la división técnica del trabajo:

En vez de hacer que el mismo artesano ejecute las diversas operaciones en una secuencia temporal, las mismas se disocian, se aíslan, se las yuxtapone en el espacio; se asigna cada una de ellas a otro artesano y todas juntas son efectuadas simultáneamente por los cooperadores [...] La mercancía, antes producto individual de un artesano independiente que hacía cosas muy diversas, se convierte ahora en el producto social de una asociación de artesanos, cada uno de los cuales ejecuta constantemente sólo una operación, siempre la misma (Marx, 1999 [1867]: 411).

En estas circunstancias, el obrero que trabaja bajo las órdenes del capitalista pierde el control del proceso de producción. En esta etapa del proceso, el obrero se presenta como un simple vendedor de su fuerza de trabajo, despojado de la esencia misma de su actividad humana: su capacidad creativa. Al respecto, Márkus afirma: "el trabajo, de libre autoactuación en la que el hombre desarrolla sus propias capacidades pasa a ser, en las circunstancias de la alienación, una actividad constrictiva, externa, que unilateraliza y deforma al individuo" (1985: 70). La siguiente cita de este mismo autor resume magistralmente el proceso de alienación:

[...] la fuerza social, esto es la multiplicada fuerza de producción que nace de la colaboración de varios individuos condicionada por la división social del trabajo, no aparece a estos individuos como su propia fuerza unificada - puesto que la cooperación misma no es voluntaria, mas espontánea - sino como un poder ajeno, exterior a ellos, del que no saben de dónde viene ni adónde va, al que, por lo tanto, no pueden dominar [...] La división espontánea del trabajo aliena necesariamente al individuo de su propia actividad productiva: por el lado del individuo, el trabajo pierde su carácter auto-activo, deja de formar multilateralmente al sujeto y de desplegar libremente la capacidad de éste [...] Por el nacimiento de la propiedad privada, el producto del trabajo se separa del trabajo, se convierte en objeto ajeno, en propiedad de otro; el objeto y resultado de la actividad se aliena del sujeto activo (Márkus, 1985: 79-83).

de mayor plusvalor por parte del capitalista, o bien como respuesta de éste a una reducción en la jornada laboral.
Sin embargo, continúa Márkus, para Marx la alienación es una fase no sólo necesaria, sino también positiva, creadora - aunque en forma contradictoria- del despliegue del ser del hombre. La disolución de las comunidades "puramente espontáneas", mezquinamente locales, no fue posible sino a través del periodo histórico y de los mecanismos de la alienación. La riqueza objetual de las necesidades y las capacidades humanas que es presupuesto objetivo de la emancipación humana no se puede constituir sino en las condiciones de la alienación (1985: 86-87). He aquí pues el carácter contradictorio del proceso de despojo por el hombre de la actividad creadora del hombre. Surge aquí la duda de si será posible que el desarrollo de la riqueza objetual conduzca a la emancipación humana y, una vez lograda, el hombre despliegue todas sus capacidades y potencialidades humanas (que le han sido "despojadas" a nivel individual), para lograr el florecimiento humano ${ }^{26}$.

De Grazia sostiene que más que la simplicidad de los movimientos realizados por los obreros en sus trabajos ${ }^{27}$ es lo impersonal del tiempo en las fábricas lo que aburre al trabajador (1994: 315). Este autor resalta la imposibilidad de los trabajadores para controlar sus actividades durante un día de trabajo. Afirma:

[...] probablemente [el trabajador] se sienta con ganas de hacer las cosas más rápidamente esa mañana, pero no puede, o puede que tenga ganas de tomar una siesta o platicar o hacer el amor o salir a tomar el aire, un trago o ejercitar diferentes músculos. Un trabajador puede estar usando ciertos músculos mientras que excluye casi totalmente a otros, de esta forma, a veces por razones que no se puede explicar, está a punto de explotar u odia la idea de levantarse por la mañana (1994: 315).

De Grazia cae en lo que Toti (1975: 104) critica en algunos otros autores, quienes al analizar el "aburrimien-

\footnotetext{
${ }^{26}$ Cabe aclarar que en estos textos de Márkus no hay una distinción explícita entre los efectos de la división social y de la división técnica del trabajo.

${ }^{27}$ Este autor señala que la operación realizada por los trabajadores no siempre es simple, sino que pueden estar en empleados en puestos en los que se realizan actividades complejas y delicadas.
} 


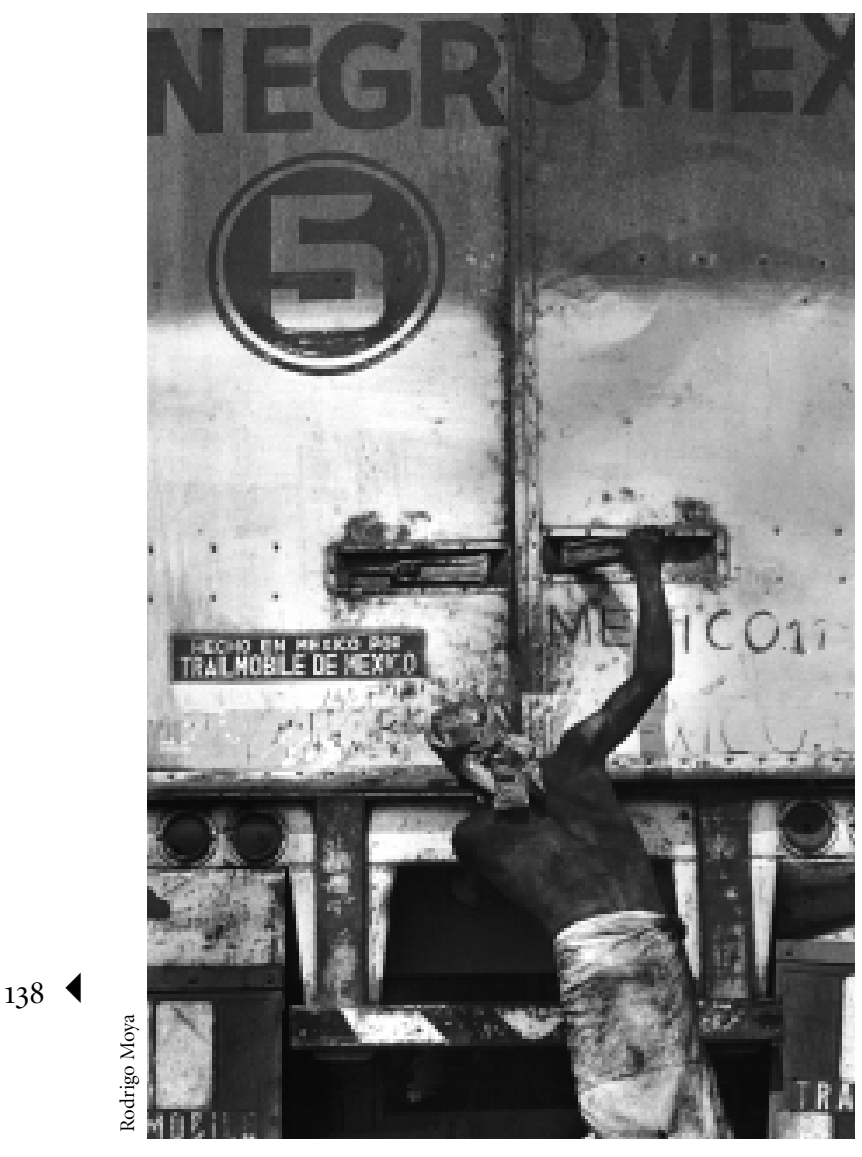

Vallejo, ciudad de México, 1967.

to" en el trabajo han identificado las cuestiones técnicas como el origen del problema. Toti cita el trabajo de Jemolo, quien sostenía:

La maldición bíblica del sudor de la fatiga ha sido sustituida por la del trabajo anónimo, sin alegría, sin un porqué visible. En una sociedad burocratizada como la nuestra, en una industria en la que el producto pasa a través de infinitos ciclos de elaboración, en un mundo de trabajo donde el resultado último es obra de infinitos colaboradores que se ignoran recíprocamente, se hace siempre más difícil, innatural, el amor por el propio trabajo (cit. en Toti, 1975: 104).

Sin embargo, para Toti, más que la despersonalización, el anonimato del trabajo moderno como la causa de que se "eche a perder y se vuelva penoso trabajar", son las relaciones sociales de producción las que provocan este sentimiento 28 .

Toti también critica a George Friedmann, uno de los estudiosos más interesados en el maquinismo industrial, por caer en el mismo error. De acuerdo con Toti, al referirse Friedmann a la crisis de la civilización industrial capitalista como una crisis del intelecto humano sostenía que:

\begin{abstract}
la crisis llega a ser así una crisis general del espíritu humano, inherente al desarrollo de las fuerzas productivas y no propia de una sociedad dominada por relaciones superadas entre las fuerzas de la producción [...] El maquinismo industrial: he aquí la causa de todos los males. Desde las máquinas de producción hasta las máquinas en general, el enemigo se insinúa en todas las dimensiones de la vida social [...] En estas sociedades, el hombre se enfrenta durante su jornada a las máquinas, el ciudadano deja una máquina sólo para pasar a otra: de la máquina con la que trabaja a la que lo transporta, al aparato doméstico, al teléfono, a la televisión (1975: 104-107)29.
\end{abstract}

Toti finaliza la crítica a estos autores sosteniendo: "esos estudiosos de sociopsicología, quienes, una vez observados agudamente los efectos del mal (la ausencia de finalidades comunes entre todos los participantes en el proceso productivo, trabajadores y patronos), deducen de ello que "la verdadera vida de muchos trabajadores no puede ser vivida más que en las horas de descanso", y por consiguiente, resuelven todos los problemas indicando la solución de una adecuada e inteligente "política de la diversión en las horas libres” (1975: 109). Sin embargo, para Toti la diversión no puede constituirse en felicidad ${ }^{30}$ si la medida de la misma es un hombre no educado en la $\operatorname{verdad}(1975: 11)$.

\footnotetext{
${ }^{28}$ Toti critica además la actitud de los sociólogos estadounidenses y de los teóricos católicos que en el capitalismo intentan devolver al obrero la alegría cristiana del trabajo y la satisfacción del trabajo.

${ }^{29}$ Para su crítica, Toti cita los textos de Friedmann titulados: Problemas humanos del maquinismo industrial, ¿A dónde va el trabajo humano? y Trabajo desmenuzado.

30 Toti retoma la concepción de Aristóteles de felicidad que consistía en la actividad contemplativa. Desarrollos sucesivos de su pensamiento han expresado que "la actividad contemplativa es la actividad del intelecto, la vida del espíritu, la filosofía, la especulación pura, el arte, todo lo que no es necesario ni útil (aunque pueda ser utilizado), y que sirve
} 


\section{ALIENACIÓN EN EL TIEMPO LIBRE}

La prolongación desmesurada de la jornada laboral responde a la hambruna de plustrabajo que experimenta el capitalismo. Marx aclara que, si bien la necesidad del plustrabajo no es exclusiva al capitalismo, la diferencia estriba en el deseo de obtener cada vez una mayor cantidad de plustrabajo, ya que en nuestra sociedad domina el valor de cambio más que el valor de uso, lo que lleva a los capitalistas a instrumentar formas que le permitan obtener una mayor cantidad de plustrabajo. De acuerdo con Marx,

cuando en una formación económica-social no prepondera el valor de cambio sino el valor de uso del producto, el plustrabajo está limitado por un círculo de necesidades más estrecho o más amplio, pero no surge del carácter mismo de la producción una necesidad ilimitada de plustrabajo (1999 [1867]: 282).

Es precisamente en el marco de esta hambruna de plustrabajo que desaparece por completo la sensación de autonomía y libertad que experimentaba el trabajador en los sistemas precapitalistas. Si bien en las primeras etapas del capitalismo no era posible formular una clara contraposición entre el tiempo de trabajo y el tiempo de libertad como categorías temporales, sociales y culturales (dado que las ocupaciones eran fundamentalmente agrícolas o artesanales), la necesidad del tiempo libre ${ }^{31}$ en la clase obrera capitalista surge, como vimos anteriormente, en la medida en que se da la apropiación paula-

\footnotetext{
únicamente para vivir del modo más elevado el propio tiempo libre, o sea, el propio tiempo personal, el propio bien individual e imposible de enajenar, la propia vida" (1975: 11). De Grazia utiliza la palabra ocio para denominar lo que Toti llama felicidad, y aclara que la concepción aristotélica de ocio es muy distinta a nuestra concepción de tiempo libre, ya que en éste no se desarrollan actividades constitutivas de la contemplación (teorizar y filosofar) ni tampoco actividades libremente elegidas. ${ }^{31}$ La concepción moderna del tiempo libre se parece a la que prevalecía en la Roma antigua. En la revisión que realiza sobre las diferentes concepciones del ocio, desde los griegos hasta nuestros días, De Grazia explica que, en latín, la palabra ocio era otium y, como en el griego, su antónimo fue construido con un prefijo negativo: negotium (1994: 21). Según este autor, entre los escritores romanos era típico encontrar descripciones del ocio como éstas: "Un hombre está ocupado —en sus actividades militares, comercio o estado, lo que sea- y posteriormente descansa y se recrea a sí mismo. La vejez en sí misma es un descanso pacífico bien ganado por el negotium" (ibid.: 22).
}

tina de todo el periodo activo de la vida del trabajador por parte del capital, escindiendo los espacios de la "vida" y el "trabajo". En este proceso se impone una nueva disciplina del tiempo, en la que se obligaba a los trabajadores (hombres, mujeres y niños) a mantener jornadas de 14 o 16 horas diarias, tiempo que fue reducido paulatinamente mediante la lucha obrera por la búsqueda de la reducción de la jornada laboral.

Algunos sectores obreros preveían que la reducción de la jornada laboral sería una condición necesaria para satisfacer necesidades en el tiempo libre como las de la educación, la socialización (con otros trabajadores) y la convivencia familiar. Sin embargo, los capitalistas veían con muy malos ojos el tiempo libre ganado por la clase trabajadora, ya que lo consideraban la madre de todos los vicios o bien un tiempo para la concientización obrera.

La ideología puritana impuesta por la nueva disciplina laboral coadyuvó a "satanizar" el tiempo libre de los trabajadores (Thompson, 1967: sección VI). Bajo esta concepción, el trabajo es una obligación divina y se rechazan los hábitos "pecaminosos" en los que la clase obrera consume su tiempo libre (los cuales eran asociados con la vagancia, el alcoholismo y la delincuencia). Se impuso una concepción moral del bien y del mal, en la que el "sacrificio" en el trabajo sería recompensado con la gloria eterna $(i b i d .)^{32}$. La moral mercantilista puritana fue acompañada por una propaganda sobre la "escasez" de tiempo y la idea de que el "tiempo es oro", por tanto, el tiempo libre es improductivo (Thompson, 1967: 90).

Además del "peligro" que implicaba que los trabajadores destinaran su tiempo libre a la vagancia y al alcohol, la burguesía se percató de que el tiempo libre se constituía en un espacio fundamental de la lucha obrera. Toti narra cómo una vez ganado el tiempo libre, diversos sectores obreros fundaron escuelas, salas de lectura, "círculos para elevar el nivel de las masas, considerado como fundamento de cualquier promoción social" (1975: 44).

\footnotetext{
$32 \mathrm{Al}$ respecto, De Grazia (1994: 27) identifica el inicio de la concepción puritana del ocio tras la caída de Roma, cuando los monjes cristianos impusieron nuevas ideas sobre cuáles deberían ser las actividades del ocio. Además de la contemplación (actividad que se vuelve sagrada, no por sí misma, sino porque en ella se busca encontrar a Dios), el trabajo, pero sobre todo el trabajo manual, se convierte en un instrumento de autopurificación, de arrepentimiento o de ayuda a otros en caridad.
} 
Ante la importancia que había adquirido la acción de las organizaciones populares durante el tiempo libre la burguesía tomó sus medidas, "sustrayendo al control del movimiento reformador un cierto número de institutos de cultura obrera, transformándolos en órganos destinados a difundir en el pueblo solamente los conocimientos y las ciencias que se revelaban útiles a la consolidación del orden moral de la burguesía" (ibid.: 45).

El capital desarrolló también actividades lucrativas que "llenaran" el tiempo libre de los trabajadores. Se crea entonces una industria del tiempo libre con sus propias reglas de consumo. Como nos dice De Grazia al respecto: "un nuevo grupo aparece en escena, aquellos cuyos bolsillos se llenan más rápido si los trabajadores, una vez que han terminado su día de trabajo, se convierten en gastadores, gastadores y frívolos" (1994: 203).

La moral cristiano-protestante impuesta por el mundo del trabajo capitalista también asignó normas al uso del tiempo libre. E. P. Thompson plantea que bajo esta ideología "es ofensivo que la fuerza de trabajo solamente pase el tiempo" (1967: 91). Por tanto, el tiempo debía ser consumido, comercializado, usado. La sociedad con tiempo libre disponible no puede desperdiciarlo, la industria del entretenimiento "trata por todos los medios de transformar al ciudadano en una termita consumidora permanente, que destruye ininterrumpidamente los productos. Incluso la sobriedad tradicional puritana se ha vuelto antieconómica y ha perdido su esmalte espiritual; el ciudadano virtuoso es el que se configura como un 'hedonista’ plácido, sometido, alistado" (Toti, 1975: 219).

De Grazia enumera (de manera irónica) las reglas que bajo esta nueva ideología consumista deben seguirse durante el tiempo libre. La primera es que la persona tiene que hacer cosas que den evidencia visible de que está haciendo algo (el autor agrega: "en Estados Unidos pensar no es considerado una actividad"). En segundo lugar, debe hacer cosas que lo ayuden a mejorar su propiedad (hágalo usted mismo), su apariencia (ejercitarse), o realizar cualquier actividad que permita hacer más dinero (1994: 307)33.

\footnotetext{
${ }^{33}$ En este punto, De Grazia pone en duda que el tiempo libre sea efec-
}

$\mathrm{Al}$ momento en que los trabajadores habían ganado tiempo libre, éste había perdido ya todo significado y era identificado con el aburrimiento. De Grazia cuenta cómo, bajo la ideología puritana a mediados del siglo XIX, el domingo se convierte en el día más muerto de la semana. El primer paso lo dio Lutero al determinar que el único día sagrado que tenía que ser observado era el domingo. Otro paso fue la reducción de los santos a la mortalidad y, por tanto, la eliminación de al menos 100 días festivos del calendario. En Londres, cuna de la industrialización, las bandas de música que llenaban los parques los domingos fueron prohibidas y se rechazó la propuesta de abrir el Museo Británico y la Galería Nacional después del servicio dominical matutino. El domingo "era un día para pasarlo en silencio y meditando, no para ir a misa y luego disfrutarla cantando, bailando, hablando, bebiendo o haciendo lo que el día ofreciera" (1994: 202-203).

La respuesta más fácil sobre qué hacer con el tiempo libre, visto como espacio de aburrimiento, es "matar el tiempo". Aparecen así los cursos para mejorar, los hobbies, la televisión, se cuenta el número de veces que se va al cine, a los museos, se sale de viaje, etc. Como lo expresa Toti: “'Relaxing hobbies!” (1975: 125). Y se organiza la gran matanza del tiempo que es, al fin de cuentas, el gran suicidio: el tiempo es el enemigo al que hay que matar. El tiempo, es decir, nuestra vida ${ }^{34}$. La industria del entretenimiento y el consumo crece y se fortalece mediante actividades que llenan y controlan el tiempo vacío de trabajo; sólo produce distracciones, valores muertos que se queman y únicamente dejan las cenizas del tiempo (ibid.: 150).

tivamente libre si consideramos que el trabajador tiene que demostrar que está haciendo algo, que existen reglas para el uso del tiempo y que tiene que decidir cada media hora o cada hora de su tiempo "libre" qué hacer.

34 Toti afirma que "está confirmado por las estadísticas — y los sociólogos del tiempo libre siempre razonan estadísticamente-que durante el tiempo libre se mata no solamente al tiempo, sino también a la gente. Los psiquiatras han descubierto que el fin de semana es un periodo crítico para las perturbaciones psíquicas provocadas por la organización social moderna" (1975: 127). Por su parte, De Grazia nos dice que al quitar el gozo al día del señor (es decir, el domingo), muchos trabajadores se dedicaron a emborracharse (1994: 203). El lento suicidio parece haber sido la respuesta. 
En su análisis sobre el uso del tiempo libre en la sociedad estadounidense, De Grazia resalta el papel que ha desempeñado la publicidad para promover los hábitos consumistas de esa sociedad y afirma: "deslumbrado por estafadores, el individuo vendió su tiempo por objetos brillantes" (1994: 223). Este mismo autor se pregunta también: “¿En qué momento las personas compran y consumen?", y responde: "En su tiempo libre” (ibid.: 275).

De Grazia pone en duda que los trabajadores estadounidenses dispongan de mayor tiempo libre en comparación con los trabajadores de mediados del siglo XIX, ya que el crecimiento de las ciudades trajo como consecuencia que el tiempo "libre", ganado mediante luchas obreras, se destinara cada día más al transporte. Pero si queda algo de tiempo libre, nuestra moderna sociedad nos ofrece entretenimiento, el cual está dominado por la televisión $^{35}$. Este autor denomina a dichas actividades (junto con otras en las que el individuo es un simple espectador) "sin pensamiento" (unthinking), más que pasivas. Toti, por otro lado, resalta el papel de control que ejercen los grandes monopolios de la cultura proporcionando "productos culturales de la clase dominante, despersonalizados, anestésicos, hipnotizantes como la televisión actual [que] penetran diariamente en el corazón mismo de las instituciones, de las casas obreras y en las capas avanzadas de la población" (1975: 46).

De Grazia agrega a las actividades enajenantes todas aquellas que proporcionan diversión y "fuga”. El trabajador ideal, afirma, necesita descansar y una distracción poco demandante o somnífera para traerlo cada día al ciclo de trabajo disciplinado y cronometrado, pero necesita también periodos en los que debe dejarse ir en el ruido y la violencia (especialmente en viernes por la noche y sábados). Además, el trabajador necesita carnavales, fiestas espirituales (año nuevo, navidades, etc.), participar o pre-

\footnotetext{
${ }^{35}$ De Grazia presenta un cuadro con datos de mediados del siglo XX sobre el porcentaje de la población de 15 años y más que declaró haber realizado una actividad de ocio la noche anterior. Se observa que el mayor porcentaje (57\%) declaró haber visto la televisión (1994: 460462). Otros estudios a los que se refiere el autor mostraron, por su parte, que nueve de cada diez hogares tenían un televisor o más, y que $90 \%$ de los televisores estaba prendido todas las noches de la semana durante cuatro horas y media en promedio por noche (1994: 113).
}

senciar competencias de equipos, etc. "El placer de hacer lo que uno no pudo durante la semana de trabajo — afirma este autor- es lo que se llama diversión" (1994: 336).

El florecimiento humano no puede realizarse durante el tiempo dedicado a las actividades "sin pensamiento", de diversión o de fuga, ya que requiere del desarrollo del intelecto. Pero además, este tipo de actividades desarrollan una audiencia acrítica, la cual tampoco es afín al florecimiento humano. Al respecto, De Grazia explica que el desarrollo de una audiencia acrítica se debe a que "los medios transmiten no comunican. No ofrecen la oportunidad de respuesta verdadera" (1994: 335) 36 .

La sociedad enajenada nada puede hacer, se enfrenta a una "libertad" controlada por la industria del consumo y la diversión de masas. Ante este panorama, surge una vez más la pregunta de si es posible el florecimiento humano en el capitalismo durante el tiempo libre.

\section{¿ES POSIBLE EL FLORECIMIENTO HUMANO EN EL CAPITALISMO?}

Para lograr el florecimiento humano se requiere contar con una serie de precondiciones para que los individuos puedan desplegar sus capacidades humanas. Sin embargo, en el sistema capitalista el desarrollo de la inteligencia del trabajador ha sido obstruido de diversas maneras. Hemos señalado la forma en que la fragmentación y alienación del trabajo provoca un desinterés en el obrero por el trabajo debido a que ha sido despojado de la visión y el control del proceso productivo. Lo anterior implica reducir la actividad creadora del hombre a operaciones sim-

\footnotetext{
36 Para este autor, la causa por la que las actividades de tiempo libre son pasivas y acríticas debe encontrarse en el cambio de tipo de espectadores. En el pasado, cualquier persona de la audiencia podía hacerse escuchar al momento, podía comunicar su acuerdo o desacuerdo con la pieza de música tocada, la obra de teatro, el discurso. Sin embargo, las actividades "pasivas" como la televisión no ofrecen esta oportunidad. Aun cuando uno pueda escribir o llamar al programa de radio o televisión para expresar su opinión, ésta no se comparte (salvo raras excepciones) con el resto de la audiencia (De Grazia, 1994: 336). El ser humano requiere de la interacción directa con otras personas. ¿Qué bien le puede hacer a un hombre gritar "muerte al imperio" a un aparato de televisión? Podrá de igual manera dormitar frente a él, asegura De Grazia.
} 
ples, constantes y repetitivas que limitan la reflexión y el desarrollo mental del trabajador. Si suponemos que tal desarrollo mental en la mayoría de los hombres está necesariamente ligado a su trabajo habitual, mientras más simple sea éste, menor será el desarrollo mental del trabajador y, por tanto, menor será su posibilidad de tener acceso al florecimiento humano.

Esta característica del proceso productivo en el capitalismo fue señalada, de acuerdo con Toti, tanto por Adam Smith como por Engels. El primero observaba que "el hombre que emplea su vida en ejecutar simples operaciones cuyos efectos siempre son los mismos o casi los mismos, no tiene oportunidad de ejercer su raciocinio, ni de poner en función sus propias capacidades inventivas para buscar medios que eliminen dificultades que nunca se presentan" (cit. en Toti, 1975: 181). Por su parte, Engels, en sus escritos, mostraba preocupación por el fenómeno de atrofia intelectual que aquejaba al obrero industrial:

[... en la fábrica moderna el obrero no desarrolla una actividad que exija de él un esfuerzo de pensamiento; pero, al propio tiempo, ese tipo de trabajo le impide ocupar su mente en otras cosas. Por otra parte, ese trabajo no ofrece ningún desahogo a los músculos, a la actividad física. De modo que no es un verdadero trabajo, sino un mero aburrimiento, o sea, la cosa más mortificante y enervante que exista; el obrero de la fábrica está condenado a ver sus energías físicas e intelectuales consumirse completamente en este tedio: desde los ochos años en adelante tiene la tarea de aburrirse todo el día [...]. En realidad, para embrutecer a un hombre no es fácil encontrar un método mejor que el trabajo en la fábrica. El obrero que trabajaba en esas condiciones no vivía, era reducido a objeto (cit. en Toti, 1975: 142).

Pero no sólo es la actividad rutinaria la que atrofia la inteligencia humana; los trabajadores se enfrentan con el cansancio producido por la intensificación del trabajo mismo. Al respecto, Toti cita a Pierrette Sartin, quien afirmaba que el cansancio humano no ha disminuido en absoluto con la mecanización, por lo menos no en la medida que se podía esperar:

Muchas son las máquinas que imponen posturas incómodas y que están mal adaptadas para los que las utilizan. A menudo son demasiado calientes, desarrollan un calor dificil de soportar, someten el cuerpo a temblores que perturban gravemente el equilibrio físico. Aun en las máquinas totalmente automatizadas, la lectura de los relojes a menudo es difícil, exige una gimnasia mental, un esfuerzo de atención que a la larga extenúa. Más de un obrero agrícola que trabaja con material muy moderno añora el tiempo en el cual su labor se realizaba con los caballos a un ritmo más lento; se queja del ruido, las sacudidas y el cansancio que resultan de las posturas que debe tomar para manejar las nuevas máquinas [...]. En cuanto al cansancio nervioso (que puede llegar hasta producir lesiones orgánicas y verdaderas neurosis) está en aumento continuo" (cit. en Toti, 1975: 261$)^{37}$.

Si bien la mayoría de los textos aquí citados se refieren al trabajo manual, la sensación de insatisfacción (o aburrimiento) también se presenta entre los trabajadores de cuello blanco (o burócratas), quienes al igual que los obreros realizan actividades que no les satisfacen ni les permiten desarrollar sus capacidades humanas. Para ilustrar lo anterior, retomo el ejemplo hipotético que Boltvinik utiliza para explicar su tipología de riquezas/ pobrezas, humanas y económicas, construidas de acuerdo con la condición del ser/estar. Este autor nos dice que consideremos a Juan, cuya profesión, la antropología física, es su pasión ${ }^{38}$. Desde el punto de vista del ser, Juan es un hombre humanamente rico, porque ha desarrollado sus capacidades (y se siente satisfecho con ellas). Sin embargo, si trabaja como burócrata realizando una actividad aje-

\footnotetext{
${ }^{37}$ De Grazia, por su parte, pone en duda la eficacia de los aparatos electrodomésticos como ahorradores del trabajo en el hogar. Se pregunta sobre los beneficio que puede tener el que una batidora bata huevos en lugar de nosotros mismos. Para comprarla y mantenerla funcionando alguien tiene que trabajar. También se pregunta: ¿cuánto se ha reducido de manera efectiva el esfuerzo de las mujeres que realizan trabajo doméstico con dichos aparatos? Según De Grazia, si bien un ama de casa estadounidense de mediados del siglo XX tenía la fuerza de hasta 90 sirvientes convertidos en aparatos, ello no parece haber reducido en igual magnitud el trabajo doméstico. Estos cuestionamientos son importantes, aunque no podemos despreciar que gracias a dichos aparatos más mujeres tienen la opción de dedicarse a actividades distintas al trabajo doméstico. La cuestión es que no necesariamente se dedican a ellas por libre elección, la mayoría comparte con los hombres el tedio y aburrimiento que no les permite tener acceso al florecimiento humano. ${ }^{38}$ Aunque esta actividad no necesariamente sea la única pasión de Juan. Boltvinik plantea la posibilidad de que dicho sujeto pueda florecer mediante otras actividades que le sean satisfactorias, como la música.
} 
na a la antropología física, Juan estaría pobre desde el punto de vista del florecimiento humano, ya que no tiene posibilidad de aplicar sus capacidades desarrolladas. En cambio, si logra obtener un empleo de antropólogo físico, Juan estaría humanamente rico (aunque su riqueza/ pobreza económica dependería del nivel de ingreso) (Boltvinik, 2005: 68-70)39. Más adelante, Boltvinik afirma:

La persona bien alimentada, sana y educada puede tener ciertas capacidades de trabajo. Aquí queda claro cómo la satisfacción de necesidades hace posible el desarrollo de capacidades de las personas. Pero en las sociedades capitalistas las capacidades individuales tienen que venderse en el mercado de trabajo para poderse aplicar. Esta venta puede ser para hacer el trabajo de sobrevivencia (Juan trabajando de burócrata) o para hacer el trabajo de autorrealización (Juan trabajando de antropólogo físico). En el primer caso, sólo aplica algunas de sus capacidades menores, mientras que en el segundo aplica sus capacidades fundamentales. Pero las capacidades tienen que venderse no sólo para aplicarse sino para hacer posible la satisfacción de las necesidades, que, a su vez, hacen posible la reproducción de la capacidad. Esta circularidad, esta integralidad entre capacidades y necesidades, se pierde en los enfoques que sólo miran un lado del asunto, como en algunos enfoques de necesidades (2005: 70).

Pero, ¿qué pasa cuando los trabajadores no pueden expresar o realizar su propia humanidad en las actividades impersonales de la producción que le son ajenas? El propio Boltvinik plantea que si Juan trabaja como burócrata para poder sobrevivir, al ser "un trabajo en el que no se autorrealiza, puede tratar de mantener como interés del tiempo libre tanto la antropología física como la música" (2005: 69.) Sin embargo, por limitaciones económicas o sociales, sus más profundas necesidades pueden desaparecer.

\footnotetext{
${ }^{39}$ La tipología de riquezas/pobrezas en las dimensiones del ser/estar desde el punto de vista humano y económico es una tabla de contingencia de cuatro entradas, por lo que las posibilidades de satisfacción de necesidades y desarrollo de capacidades son diversas y dependen de la celda en la que se ubique el individuo. Por ejemplo, desde el punto de vista económico, Juan podría ser rico (o tener satisfechas sus necesidades) en un empleo en el que humanamente sea pobre, ya que aun cuando ganara lo suficiente realizaría actividades ajenas a lo que considera su pasión, la antropología física.
}

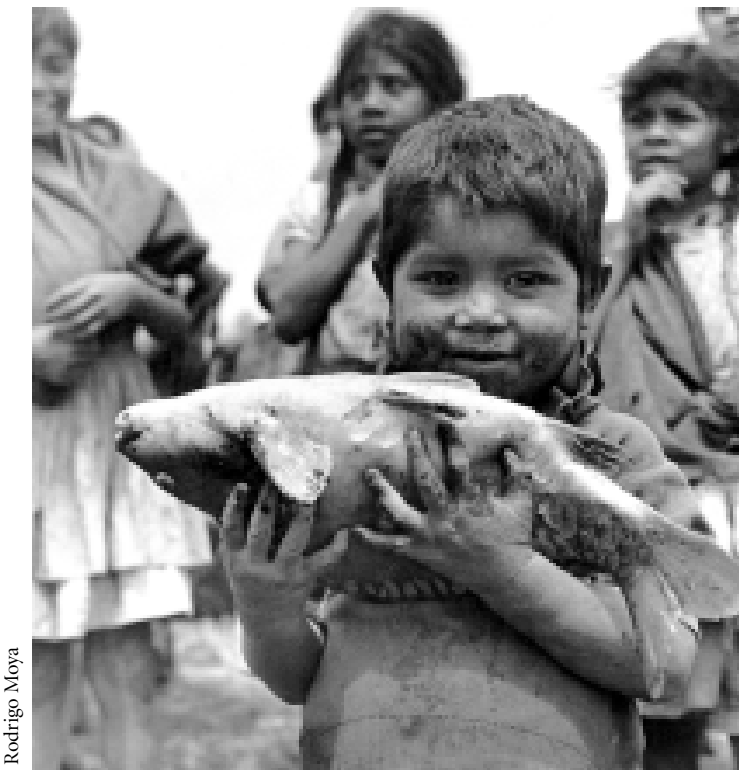

Opopeo, Michoacán, ca. 1972.

A pesar de que algunos individuos puedan sobreponerse a las limitaciones que el modo de producción impone para lograr su florecimiento humano, la inmensa mayoría "busca su libertad en lo que considera como lo contrario absoluto del reino de la imposición; es decir, las actividades de entretenimiento de masa" (Toti, 1975: 181). De esta manera, la idea de tiempo libre se impone sobre la de la libertad para el propio desarrollo.

Para Toti, el problema de la libertad y del tiempo de libertad se confunde con el problema del aburrimiento que no logra ser superado mediante el entretenimiento. Surge así la preocupación por la ampliación del tiempo a disposición del hombre - un tiempo que es siempre más difícil controlar y llenar de contenidos. El hombre del tiempo libre se vuelve entonces objeto de preocupaciones, ya que aparece precisamente como un objeto, como un vacuum por llenar, una pasividad, una inercia que hay que activar. Al respecto, este autor plantea que en el capitalismo, la cultura y la recreación popular aparecen como actividades en las que se requiere hacer un consumo "más inteligente" del producto tiempo. La cuestión cultural se presenta como un problema de programas educativos para los adultos y jóvenes, en vez de un pro- 
blema de lucha global por una sociedad distinta (Toti, 1975: 173-175).

Pero, ¿ cómo imaginar una sociedad distinta basada en la búsqueda universal del florecimiento humano (o unificación del tiempo de trabajo y el tiempo libre) cuando el desarrollo del intelecto ni siquiera es considerado un valor en la actual sociedad moderna? Toti propone que para solucionar el problema del aburrimiento del trabajador, es decir, para lograr el florecimiento humano, no se debe buscar tanto mejorar las armas para asesinar al tiempo: los medios de diversión, los sistemas de utilización del tiempo libre, sino más bien devolver al tiempo libre un significado (1975: 181). Para este autor, el tiempo libre debe transformarse

en un tiempo de conciencia, un tiempo de lucha por librarse del trabajo, una relación consciente - también en la diversión y en el entretenimiento- de la contradicción entre el trabajo y el tiempo libre, de la necesidad de volver a reunificar el tiempo del hombre, de reconstruir al hombre en toda la dimensión temporal de su existencia, como agente primero de la sociedad, como creador de la sociedad. Pero, para llegar a este resultado, hay que partir de la búsqueda de una conciencia de las contradicciones sociales, o sea, hay que partir del trabajo, de las estructuras de la sociedad y no de sus superestructuras, es decir, del tiempo libre (1975: 181).

Sin embargo, Toti contesta sólo de manera indirecta la pregunta sobre la situación que resultaría, en términos de creatividad del trabajo humano, si se abolieran las relaciones capitalistas de producción sin transformar el proceso productivo. Al finalizar la crítica a diversos autores que ponen el acento en la división técnica del trabajo como causa de la alienación del trabajo (Fromm, Riesman, Friedmann), alude (sin precisarlas) a las "dificultades que sin duda se deberán superar en la sociedad socialista para realizar 'individuos de desarrollo integral'”. Más adelante, Toti se pregunta, pero no responde: “¿Cómo reaccionan física y mentalmente los millones de trabajadores soviéticos ante sus respectivos trabajos fraccionados, los trabajos en cadena?" (1975: 172) ${ }^{40}$. No

${ }^{40}$ Luis Arizmendi es muy crítico de los sistemas sociales denominados socialistas, bajo el argumento de que el socialismo realmente existente es un "Estado capitalista despótico" (véase su artículo en este mismo obstante, afirma que se requieren "modificar las relaciones de producción existentes, que transforman en mercancía también el tiempo libre del hombre". Hasta que no se consiga cambiar esta sociedad, sólo se podrá constatar amargamente que "la espontaneidad del hombre cesa de existir, también en el uso de su tiempo libre, en el momento en que se hace un esfuerzo excesivo para 'alcanzarla', o sea, para comprarla" (1975: 111).

Podemos decir que si bien la unificación plena del tiempo de trabajo y el libre en una síntesis humana superior pasa por la transformación de las relaciones sociales, en tanto no hayamos alcanzado tal transformación, tenemos que hacer "uso" de la superestructura, es decir, del tiempo libre, para crear la conciencia de la existencia de las contradicciones sociales que permita esta síntesis. De lo contrario, el florecimiento humano aparece lejano, si no imposible ${ }^{41}$.

\section{REFLEXIONES FINALES}

En el capítulo final de su libro, Toti concluye: "actualmente, las clases subalternas son mantenidas en un nivel cultural bajo, o sea, en el nivel de una recreación al estado puro, sin preocupaciones informativas ni culturales, en el nivel de la diversión, o sea, de la divagación, de la distracción, y no de la atención ni la contemplación" (1975: 258). A más de cuatro décadas de que Toti llegara a esta conclusión (la versión original del texto en italiano fue

número). No obstante, no puede negarse que, en términos de derechos laborales, durante su existencia servía de freno y contrapeso al desarrollo del capitalismo voraz que prevalece actualmente y que niega los derechos fundamentales a los trabajadores, sobre todo en los países más pobres.

${ }^{41}$ De Grazia plantea dos condiciones necesarias para lograr el acceso generalizado a la posibilidad de disfrutar el ocio. La primera es que el Estado debe transformarse para lograr proveer las condiciones materiales que permitan a todos la posibilidad de disfrutar el ocio (aunque plantea que no necesariamente todos llegaremos a él dadas nuestras diferentes capacidades) (1994: 435). Sugiere también que es necesario romper el ansia consumista, ya que aniquila toda posibilidad de disfrutar el ocio debido a que la espiral de producción-trabajo-necesidad de tiempo de consumo no se detiene. Lo anterior implicaría modificar la idea estadounidense de que la posesión de bienes los coloca en la cima del nivel de vida (1994: 345). 
escrita en 1961) la situación de la clase obrera en el mundo se ha agravado con la globalización y la derrota del socialismo realmente existente. Cada día aparece más remota la posibilidad de que el trabajador logre trascender el grado de alienación en el que se halla y encuentre el camino al florecimiento humano.

Además del tedio en el trabajo y la vacuidad de la cultura de masas, un aspecto ignorado en el planteamiento tanto de Toti como de Boltvinik es el desgaste de la fuerza de trabajo en el transporte. Si bien el uso de la Internet ha logrado que una pequeña proporción de la fuerza de trabajo, sobre todo la que realiza trabajo intelectual, no tenga necesariamente que enfrentarse al agotamiento que implica el traslado en las grandes ciudades y suburbios de nuestra "moderna" sociedad, para la gran mayoría de los trabajadores llegar a sus lugares de trabajo representa casi media jornada laboral "normal" (o sea cuatro horas diarias) ${ }^{42}$. Como lo expresa Toti casi al final de su obra, "la música culta requiere una atención que ya ha sido totalmente gastada en el trabajo" (y en el transporte, habría que añadir).

Se podría argumentar que el tiempo destinado al transporte puede convertirse en un espacio para la concientización. Al recordar, por ejemplo, que una de las grandes revoluciones de la cultura obrera en Inglaterra fue la producción de los llamados libros de bolsillo, podríamos decir que en las actuales circunstancias los aparatos electrónicos de "bolsillo" que permiten la reproducción de libros grabados, de música y radio aparecen como una nueva opción de concientización ${ }^{43}$. Sin embargo, surge la pregunta: ¿en qué grado estos nuevos instrumentos (tanto electrónicos como de Internet) lograrán transformar la conciencia de clase para buscar como fin último el florecimiento humano, si es la industria capitalista de masas la que decide los productos que pueden estar disponibles en el mercado para las mayorías?

\footnotetext{
${ }^{42}$ Como hemos apuntado, De Grazia cuestiona constantemente la idea de que en la actualidad gozamos de mayor disponibilidad de tiempo. Además de alertarnos sobre el aumento en el tiempo destinado al transporte, asegura que el crecimiento de las ciudades provocó la destrucción de los espacios comúnmente utilizados por la fuerza de trabajo en sus tiempos libres, como por ejemplo, áreas verdes, ríos, etcétera. ${ }^{43}$ Sobre todo en una sociedad como la mexicana en la que la lectura es poco común entre la clase trabajadora, no se diga entre la "culta".
}

Y aquí conviene retomar la cita que hace Toti de Marx en la que éste duda sobre el fin último de la creación de nuevos productos (valores de uso/valores de cambio) en el capitalismo:

Junto con la masa de los objetos crece, pues, el reino de las instituciones exteriores a las cuales el hombre está sometido; y cada nuevo producto es una nueva potencia de engaño recíproco y recíproca explotación [...] La expansión de los productos y de las necesidades se vuelve esclava ingeniosa y siempre calculadora de apetitos inhumanos, refinados, poco naturales e imaginarios. Por un lado, hay un refinamiento constante de necesidades y medios; por el otro, un regreso a la barbarie animalesca, una simplificación de las necesidades, completa, tosca, abstracta [...] De allí la necesidad de llevar a las masas trabajadoras a la lucha por reivindicaciones siempre más elevadas, de cultura, de belleza también, relativas a las condiciones de existencia (cit. en Toti, 1975: 263).

Aunque el enfoque del florecimiento humano plantea que en el capitalismo la disponibilidad de tiempo libre ocupa un lugar central dado que la mayoría de los individuos tiene empleos poco satisfactorios, la posibilidad de lograr a nivel societal el florecimiento sólo se dará en una etapa histórica superior al capitalismo en la que no se presente la escisión humana. Lo anterior se deduce de la cita a Márkus que realiza Boltvinik (2005: 62) casi al inicio de su obra:

[...] la producción capitalista, en cuanto forma suprema de la alienación, no es sino el estadio específico de la evolución de las fuerzas productivas sociales en el que éstas se desarrollan como fuerzas del capital independizadas frente al trabajador y, por lo tanto, en contraposición directa a su propio desarrollo, al desarrollo del trabajador. Dicho más precisamente, la misma alienación no es sino esa discrepancia en la cual la evolución histórica de la humanidad discrepa de la evolución de los individuos, y el efecto autoconfigurador, autodesarrollador de la actividad humana aparece sólo en el plano social global, y no como factor configurador del individuo, desarrollador de la personalidad en la actividad del individuo mismo. La alienación no es, pues, según el uso conceptual de Marx, más que la contraposición, la escisión entre el ser humano y la existencia humana. Y la abolición-superación de la alienación es la abolición de la contraposición entre el ser humano y la existencia humana, o sea, la creación de las posibilidades de una evolución his- 
tórica en la cual se termine la contraposición entre la riqueza, la multilateralidad de la sociedad y la impotencia, la mezquindad, la unilateralidad de los individuos, una evolución en la cual el desarrollo general de la sociedad, el estadio evolutivo de la humanidad, se pueda medir adecuadamente por el estadio de desarrollo de los individuos, y la universalidad y libertad del género humano se exprese directamente en la vida multilateral y libre del individuo (Márkus, cit. en Boltvinik, 2005: 62).

Pero mientras llega el tiempo (aunque en sentido estricto sería el momento histórico) en el que se dé la abolición de la alienación, tanto Toti como Boltvinik establecen que para que se de la reunificación entre el ser humano y la existencia humana, primero la humanidad debe satisfacer las necesidades deficitarias (en el sentido de Maslow). Al respecto, Toti cita a Marx en un texto en el cual, al referirse al socialismo (como ideal de sociedad), éste sostiene que:

El hombre podrá producir de modo universal, libre de la necesidad física precisamente porque produce de verdad sólo humano perderá su naturaleza egoísta, puesto que el hombre será "rico y profundamente sensible a todo". La historia habrá cumplido su tarea, que es la de predisponer las condiciones para que los hombres se conviertan en objeto de la conciencia sensible y para que la necesidad del hombre se transforme en necesidad humana. Ser ya no será tener; en lugar de la riqueza y la miseria existirán el hombre rico y la riqueza de necesidades humanas. El hombre será "rico", o sea, necesitado de una totalidad de manifestaciones de vida humana, y su realización será una necesidad interior [...] El hombre será deudor de su propia existencia sólo consigo mismo, y finalmente será libre y verdaderamente independiente. La generación del hombre mediante el trabajo humano se habrá cumplido (cit. en Toti, 1975: 275-276).

El florecimiento humano aparece en la actualidad como una característica de un escaso número de hombres y mujeres cuyo trabajo elegido libremente (remunerado o no) les ha permitido desplegar todas sus potencialidades humanas ${ }^{44}$. La generalización del florecimiento hu-

${ }^{44}$ No obstante, el desarrollo de capacidades y necesidades humanas

mano, como forma de vida (al menos para la mayoría de la sociedad) pasa necesariamente, como plantea Marx, por la desaparición de la antítesis entre tiempo de trabajo y tiempo libre. No obstante, esta conclusión social supone "una libertad casi absoluta del hombre con respecto a la producción de los medios materiales de subsistencia $y$, por consiguiente, su indiferencia hacia los problemas de la propiedad de los medios de producción" (Marx, Grundrisse, cit. en Toti, 1975: 269-270). Esta condición seguramente se cumplirá en Utopía.

\section{Bibliografía}

Boltvinik, Julio, 2005, Ampliar la mirada. Un nuevo enfoque de la pobreza y el florecimiento humano, tesis para obtener el doctorado en ciencias sociales, Centro de Investigaciones y Estudios Superiores en Antropología Social (CIESAS)-Occidente.

De Grazia, Sebastian, 1994 [1962], Of Time, Work and Leisure, Vintage Books, Nueva York.

Maslow, Abraham, 1943, "A Theory of Human Motivation", Psychological Review, vol. 50, pp. 370-396.

Márkus, György, 1985 [1971], Marxismo y 'antropologia', Grijalbo, México.

Marx, Karl, 1999 [1867], El capital, Siglo XXI, México, Madrid (Biblioteca del Pensamiento Socialista) ( $1^{\text {a }}$ ed. en español, 1975).

Oxfam, 2004, Trading Away our Rights, Women Working in Global Supply Chains, Oxfam International, Oxford, Gran Bretaña.

Thompson, E. P., 1967, "Time Work-Discipline, and Industrial Capitalism", Past \& Present, A Journal of Historical Studies, núm. 38, diciembre, The Past and Present Society, pp. 56-97.

Toti, Gianni, 1975 [1961], Tiempo libre y explotación capitalista, Ediciones de Cultura Popular, México.

también se da en individuos cuya actividad no es elegida libremente y que están sometidos a trabajos agobiantes y extremos. Un ejemplo de estos casos puede ser el de Espartaco, quien, a pesar de su condición de esclavo, logra mantener una rebelión de esclavos en contra del imperio romano por más de cinco años. Engels también aseguraba que los obreros, a pesar de estar sujetos a condiciones laborales extremas, habían conseguido no solamente salvar su intelecto, sino desarrollarlo y afinarlo más que la otra gente gracias a su rebelión contra el destino y la burguesía, o sea, gracias al único pensamiento o sentimiento que podían cultivar durante el trabajo" (cit. por Toti,1975: 42). Tal rebeldía llevó al obrero a impulsar métodos y medios de lucha para autoeducarse en su escaso "tiempo libre" (después del trabajo, en los traslados, en la comida, etc.). 